\title{
Macroeconomic surprises, market environment, and safe-haven currencies
}

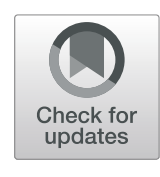

Adrian Jäggi ${ }^{1}$, Martin Schlegel ${ }^{2}$ and Attilio Zanetti ${ }^{3 *}$ (D)

\begin{abstract}
We study the reaction of the CHF and JPY to macroeconomic surprises and changes in the broader market environment before and during the crisis using high-frequency data. Results show that the CHF and JPY are traditionally more sensitive to macroeconomic surprises than other currencies, reflecting the fact that macroeconomic surprises impact uncertainty and risk aversion. This link was further magnified during the crisis and could not be broken by the specific measures adopted by monetary authorities to limit the appreciation trend. We also find some evidence that, during the crisis, CHF and JPY responded more strongly to surprises generating an appreciation than to surprises leading to a depreciation. Additionally, both currencies also systematically respond to changes in the general market environment. This result is robust to the use of two measures of the market environment: VIX and on a novel index based on Bloomberg wires.
\end{abstract}

Keywords: Safe-haven currencies, Swiss franc, Yen, Macroeconomic surprises, Risk

JEL Classification: F31, G12, G14

\section{Introduction}

The Swiss franc (CHF) and the Japanese yen (JPY) are prominent safe-haven currencies. Their specific safehaven status has been documented among others by Fatum and Yamamoto (2016), Auer (2015), De Bock and De Carvalho Filho (2015), Botman et al. (2013) as well as Ranaldo and Söderlind (2010). In times of increased global risk aversion, these are the only currencies that appreciate against all other currencies, including the US dollar (USD).

The troubled times experienced by the world economy after the outburst of the subprime crises in August 2007 have brought about further evidence of the safe-haven status of these two currencies. With the intensification of the international crisis, both currencies experienced waves of massive appreciation. The magnitude of the appreciation and its consequences in terms of deflationary pressures and output loss in the face of the zero-lower bound constraint forced monetary authorities in the two countries to adopt unconventional policies to limit the appreciation

*Correspondence: attilio.zanetti@snb.ch

${ }^{3}$ Economic Analysis Unit, Swiss National Bank, and University of Basel, Basel, Switzerland

Full list of author information is available at the end of the article of their currencies in order to achieve their broader policy goals ${ }^{1}$. As depicted in Fig. 1, this is reflected in the unique increase in the Swiss National Bank (SNB) and Bank of Japan (BoJ) balance sheets. In this paper, we will summarize the adoption of these unconventional monetary policies under the term regime change ${ }^{2}$.

The safe-haven status of these currencies implies that the demand for CHF and JPY is crucially driven by shocks that raise the general level of uncertainty on the international financial markets. This principle, however, leaves a series of questions open. To which pieces of information do safe-haven currencies really react? Are responses symmetric? How was this link influenced by the crisis? Does a stronger monetary policy focus on the exchange rate modify or even break the link?

An abundant literature has investigated the connection between macroeconomic surprises-defined as the difference between the value released and the corresponding market expectation for a given macroeconomic indicator-and asset prices. These studies have shown that unexpected developments in macroeconomic indicators can generate significant and rapid reactions in asset prices. The standard view in this literature is that macroeconomic surprises are perceived by market participants as a change in fundamentals for a given economy. This leads, 


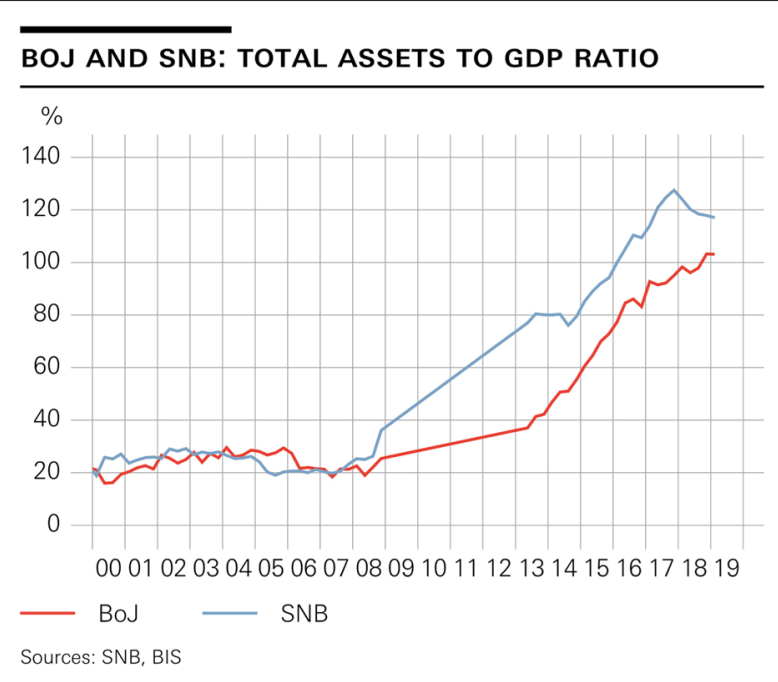

Fig. $1 \mathrm{BOJ}$ and SNB: total assets to GDP ratio

in turn, to a reassessment of the future monetary policy stance and thus to a repricing of assets.

However, macroeconomic surprises can be seen not only just as a source of information that feeds into a revised baseline scenario but also as a factor affecting uncertainty. News reflecting unanticipated economic weakness may spark risk aversion and foster the demand for safe assets ${ }^{3}$. Conversely, any piece of information that points to stable and balanced international growth may reduce markets' risk aversion and thus the demand for safe-haven assets. If this is the case, one should expect safe-haven currencies to be particularly sensitive to macroeconomic surprises and crises times to further accentuate this sensitivity.

The circle of factors that may influence risk perception is obviously much wider and disparate than standard macroeconomic indicators. The general market environment, as we will call it, may be affected by factors like corporate news or even rumors, economic policy news, political news, and more. The trouble with these potential sources of uncertainty and market volatility is that they are much harder to measure in a systematic way than standard macroeconomic surprises. That is why research traditionally takes an indirect approach: a popular proxy for general market uncertainty and risk aversion is the CBOE VIX index of implied volatility of the S\&P 500 index options. In this paper, we rely on the standard VIX measure as well as on a novel index based on Bloomberg wires to capture broad market-environment conditions.

Based on a very broad sample of high-frequency data covering the period between January 2000 and December 2013, we study the effect of macroeconomic surprises stemming from ten different economies, the general market environment and the monetary policy regime on the
CHF and JPY exchange rates. We show, first, that safehaven currencies are much more responsive to macroeconomic surprises than other currencies. In our regressions for the JPY and CHF, we obtain $R^{2}$ that are higher than benchmark results in the literature. The same message emerges when running regressions for a control group of currencies: Australian Dollar (AUD), Canadian Dollar (CAD), and British Pound (GBP) are substantially less sensitive to macroeconomic surprises than $\mathrm{CHF}$ and JPY. Second, we find strong evidence that the sensitivity of CHF and JPY to macroeconomic surprises was substantially magnified by the crisis. Third, this observation is resilient to the changes in monetary policy regimes cited above. Fourth, we find some evidence of asymmetries: both currencies tend to display larger reactions when a surprise provokes an appreciation than when it causes a depreciation. Finally, according to our results, swings in the general market environment affect exchange rates on top of standard macroeconomic surprises. Market environment and macroeconomic surprises are thus complementary factors.

The Bloomberg-based variable turns out to be strongly correlated with the VIX index. On the one hand, this further legitimizes the use of VIX as a proxy for marketenvironment conditions. On the other hand, however, our alternative market-environment measure displays various convenient features when compared to the VIX. First, it is not influenced by the macroeconomic surprise variables that we employ. Secondly, it is not bounded at zero and can thus fluctuate in an untruncated manner. In doing so, it captures phases of strongly positive market sentiment better than VIX. Our results do indeed suggest that the Bloomberg-based variable is better positioned than VIX to capture the impact of extreme conditions on safe-haven currencies.

This paper is organized as follows. The next section summarizes the lessons learnt from the existing literature. Section 3 describes our dataset and defines our variables. Section 4 sketches our empirical approach and presents the results while Section 5 concludes.

\section{Relevant literature}

A large body of literature has used high-frequency data to study the impact of macroeconomic surprises on asset prices: equities, exchange rates, treasury bills, bonds, and forward rates. Generally speaking, there is broad-based evidence that macroeconomic surprises can produce significant changes in asset prices ${ }^{4}$. These changes tend to occur very rapidly after the surprise is observed (Pearce and Solakoglu (2007); Andersen et al. (2003); Dominguez (2003). Not all assets are impacted equally. Goldberg and Leonard (2003) show that the effect of macroeconomic surprises are systematically stronger on the short end of the yield curve than on the long end. Bartolini 
et al. (2008) and Andersen et al. (2007) find that macroeconomic surprises have their strongest impact on interest rates while the impact is less pronounced for exchange rates and equity prices. The effects on interest rates and exchange rates appear to be longer-lasting than the effects on equity prices. Swanson and Williams (2014a) find that interest-rate reactions to macroeconomic surprises are less pronounced when the economy operates at the zero lower bound. Similarly, Goldberg and Grisse (2013) argue that the responsiveness of asset prices to macroeconomic surprises can vary over time with various states of the economy. A prominent feature of different studies is the dominance of US macroeconomic variables. Goldberg and Leonard (2003) show that while US macroeconomic surprises have a distinct impact on European yields, the evidence for a reverse influence is very limited. German yields appear to be more responsive to US surprises than to German or euro area surprises. Andersen et al. (2003) show that the impact of US surprises on the USD/DM exchange rate is much more substantial than the impact of German macroeconomic surprises. Recent papers have focus on the responsiveness of exchange rate to macroeconomic news in the crisis. Ben Omrane and Savaşer (2017) focus on the euro, pound, and yen against the US dollar in the 2005-2009 period. They find that the exchange rate volatility response to most news indicators is largest in expansions. An exception is represented by US housing starts and Fed fund rates decisions, which display a larger impact on currencies with the start of the subprime crises. Cheung et al. (2017) focus on the JPYUSD cross. They find that in the crisis, the average effect of US macro surprises has roughly doubled while Japanese news appear to be irrelevant.

The safe-haven status of the CHF and JPY has been documented by Ranaldo and Söderlind (2010), based on an analysis of all major currencies' reactions to various financial market shocks over the period 1993-2008. JPY and $\mathrm{CHF}$ appreciate in a systematic way when risk peaks. In the most extreme instances, the appreciation of these two currencies is non-linear in the increase in risk. The measure of risk that appears to matter most is FX market volatility, i.e., FX-specific risk rather than general measures of risk such as the VIX. In their effort to identify what characterizes a safe-haven currency, Habib and Stracca (2012) also fail to find a stable link between the VIX and the currencies of advanced economies. Instead, they find that an increase in the VIX is systematically associated with depreciations of emerging market currencies. De Bock and de Carvalho Filho (2015) use spikes in the VIX to define risk-off episodes and show that in such periods returns on the CHF and JPY outperform those of all other currencies. Yeşin (2016) finds that the VIX displays stronger co-movements with the CHF real effective exchange rate than do capital flows to and from
Switzerland. Thus, the evidence on the usefulness of the VIX as a measure of global risk aversion to explain the behavior of safe-haven currencies is mixed.

\section{Data sources and variables definition}

\subsection{Exchange rates}

We work with a dataset covering the period from January 1, 2000 up to the end of 2013, at a 5-min frequency. All in all, the full sample includes $1,472,832$ observations for each exchange rate cross. Nominal exchange rate data are taken from the Swiss National Bank database and originate from the EBS trading platform. We focus on following exchange rate crosses: EURCHF, USDCHF, EURJPY, and USDJPY. The notation of the currencies is such that a rising (falling) value in the quotes represents a depreciation (appreciation) of the safe-haven currency. For each point in time, we dispose of bid and ask quotes as posted on EBS, and compute transaction prices as the average between the two. In the absence of formal quotes, the price at time $t$ is computed on the basis of the latest quotes observed. We remove weekends from our data sample and focus on trades occurring between Sunday 11:00 pm and Friday 9:00 pm British Standard Time (BST). For simplicity's sake, all variables are matched to a continuous time vector (without summer time). Returns are computed as logarithmic differences:

$\Delta f x_{t+1}=\ln \left(F X_{t+1}\right)-\ln \left(F X_{t}\right)$ where the interval between $t$ and $t+1$ in our baseline specification lasts five minutes.

\subsection{Macroeconomic surprises}

The database on macroeconomic news and market expectations is provided by Haver Analytics, which has taken over surveys that were originally conducted by Money Market Services. The database includes the precise time of the official data release, the number released and the corresponding market expectation. Expectations are defined as the median forecast over all market participants included in the survey. These data sources are the reference in the existing literature on macroeconomic news (Andersen et al. (2003), Gürkaynak et al. (2005), Swanson and Williams (2014a,b)). Our initial dataset groups together information for ten economies: Switzerland, USA, euro area, Germany, France, Italy, Spain, Belgium, the UK, and Japan.

Following a well-established approach, we compute macroeconomic surprises at time $t$ for any given macroeconomic indicator $k$ as the difference between the released number $\left(R_{k t}\right)$ and the value expected by market participants, $E_{k t}$. Also, in order to facilitate a comparison of the relevance of various surprises across macroeconomic indicators, surprise variables are standardized as in Balduzzi et al. (2001) by dividing the surprise by its sample standard deviation. 
Hence, our surprise variables are defined as follows:

$$
S_{k t}=\frac{R_{k t}-E_{k t}}{\hat{\sigma}_{R_{k t}-E_{k t}}}
$$

If the data released correspond precisely to the expected value, $S_{k t}$ will be equal to zero. Note that, by construction, each time series $S_{k t}$ is predominantly composed of missing values, as announcements for any variable $k$ only occur once a month or once a quarter. Regressions below will focus only on exchange rate changes when surprises are available.

\subsection{Market environment}

Surprises stemming from standard macroeconomic indicators are not the only factors that move asset prices. Qualitative information often plays a crucial role. Any unexpected piece of news that might impact the (future) performance of the economy can affect financial markets' mood-risk aversion and market expectations-and thus move asset prices. The spectrum of potentially relevant information is broad. It includes further macroeconomic news (such as growth projections, budget or public debt numbers), macroeconomic policy announcements (such as structural reforms), individual companies' information, and national or international political events. We summarize these elements under the term market environment.

A major problem naturally exists in the concrete measurement of the factors affecting the market environment. In order to incorporate this crucial aspect in our analysis, we take two different routes. The first is an indirect route. We identify the market environment measure with the inverse of the CBOE VIX index of implied volatility of the S\&P 500 index options, a proxy for general financial market uncertainty and risk aversion. This same approach is taken in an abundant number of contributions in the literature. We name this first market-environment variable, VIX .

The second and more novel approach is based on Bloomberg wires. A Bloomberg algorithm allows us to count stories as reported in the wires on a daily basis according to desired filtering criteria. Users have various options. They can create their own story counts by using key words or by selecting and combining specific topics. Alternatively, they can rely on pre-defined story counts as provided by Bloomberg itself. The algorithm distinguishes between positive and negative news according to their historical relevance for markets. Our second market-environment variable, $B B_{t}$, is derived as the simple difference between two very broad-based predefined topics, "positive" and "negative," as computed by Bloomberg itself. Under the first topic, the algorithm counts all "potentially positive news." Under the "negative" topic, the algorithm records all stories which appear to be "potentially negative news." The definition of "potentially positive" and "potentially negative" is entirely empirical and rests with the Bloomberg algorithm. To provide the reader with a sense of which pieces of news are incorporated in this variable, Table A1 in the Appendix lists the 38 top-ranked "negative" pieces of news taken into account in the computation of the story count on the day that $B B_{t}$ reached its lowest absolute value in our sample (March 13, 2011). It is important to stress that $B B_{t}$ does not contain macroeconomic data releases and thus does not overlap with our standard macroeconomic surprises.

$B B_{t}$ is so defined that negative values correspond to days when negative news dominates. Figure 2 compares normalized versions of $B B_{t}$ and the inverse of VIX (corresponding to our $V I X_{t}$ ), so that negative values correspond in both cases to a risk-averse environment. The two variables are highly correlated but not identical. At a daily frequency, $B B_{t}$ is much more volatile. In the 2003 to 2007 period-generally speaking, a time of expansion and stability of the world economy $-B B_{t}$ still displays repeated negative spikes while $V I X_{t}$ does not. From 2011 onwards, the two variables diverge. While $V I X_{t}$ goes back to the positive territory, in our logic pointing to a reduced demand for safe havens, $B B_{t}$ remains mostly negative.

Figure 3 shows the daily changes in the two variables. Clearly, the second part of the sample displays a systemically higher volatility in market-environment conditions than the pre-crisis period. In this period, it is not uncommon to observe fluctuations in $B B_{t}$ in the order of magnitude of four standard deviations from 1 day to the next.

\section{Empirical analysis}

\subsection{The role of macroeconomic surprises}

A recurrent result in the existing literature is that US macroeconomic surprises often have a stronger impact on any country's asset prices than national surprises. Given their safe-haven function, one can expect the JPY and CHF to respond to a broader range of international macroeconomic surprises than other asset prices. Accordingly, beyond the domestic indicators, we included news originating from several other countries in our universe of potential explanatory variables: the US, the UK, Germany, France, Italy, Spain, Belgium, and the euro area as a whole. There are two reasons for including individual euro-area countries. First, some individual country data are released faster than the aggregated euro area data, and hence provide early signals for the area as a whole. Secondly, we want to be able to isolate the impact of macronews stemming from specific countries that attracted significant market attention during the European debt crises. 


\section{Market Environment Measures}

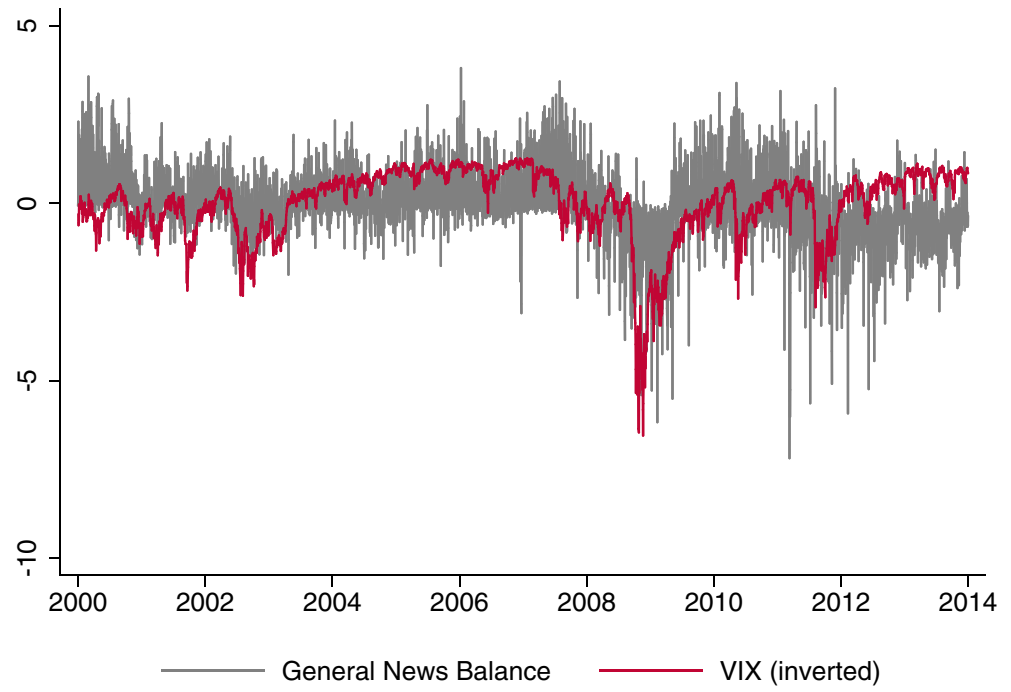

Fig. 2 Bloomberg vs VIX

In a first step, we estimate the following model:

$$
\Delta f x_{t+1}^{c}=\alpha^{c}+\Delta f x_{t}^{c}+\sum_{k=1}^{K} \beta_{k} S_{k, t}+\varepsilon_{t}^{c},
$$

where $\Delta f x_{t+1}^{c}$ are the 5-min returns of the exchange rate cross $c . \beta_{k}$ captures for each macroeconomic variable $k$ the magnitude of the exchange rate reaction to any surprise $S$ that occurs at time $t . \beta_{k}$ coefficients can be interpreted as the percentage point changes in the exchange rate generated by a one-standard-deviation surprise. Coefficients estimates stem from OLS regressions. $t$-statistics are computed using heteroskedasticity and serial correlation consistent (HAC) standard errors.

The number of explanatory variables initially considered is very large. We operate a first broad screening by regressing our four exchange rate crosses on the complete list of non-domestic $S_{k}$ variables. We refer to the $10 \%$ significance level as the selection threshold. Regression results are not reported in this paper. They reveal a first clear verdict: macroeconomic news stemming from France, Italy, Spain, Belgium, and the UK have no material relevance for the JPY and CHF. We thus remove them all from the set of explanatory

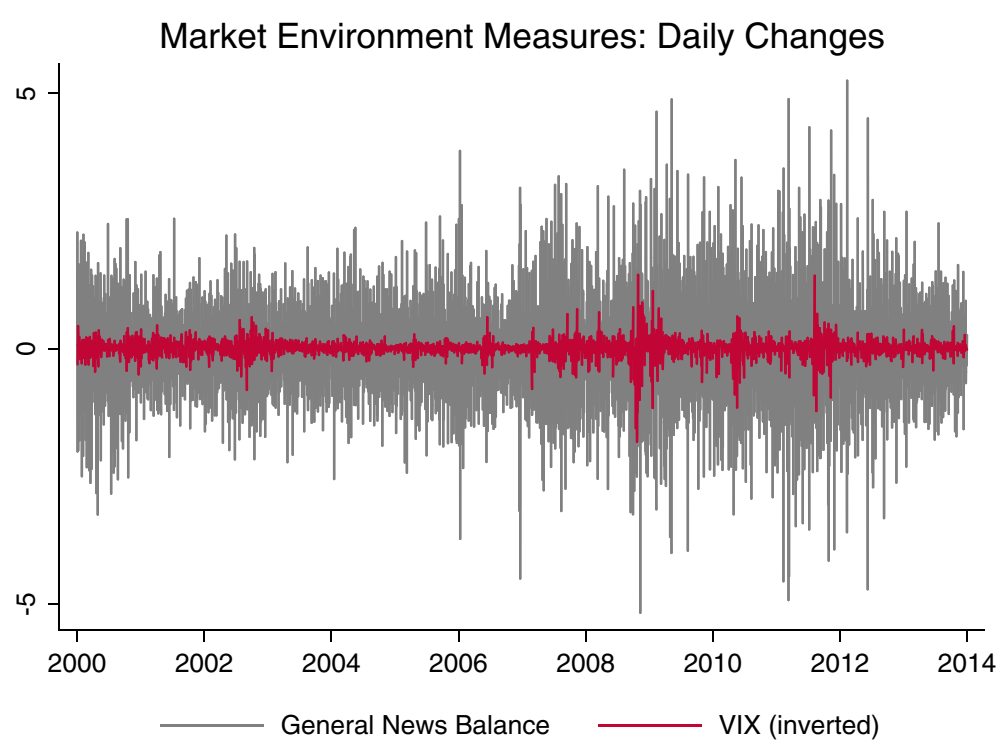

Fig. 3 Daily changes in $B B_{t}$ and $V I X_{t}$ 
variables. We will return later to the meaning of this outcome.

In a second step, EURCHF and USDCHF returns are regressed on all US, German, and euro area macroeconomic surprises in addition to Swiss macroeconomic surprises. The same exercise is made with EURJPY and USDJPY, where Japanese surprises are used instead of the Swiss variables. Only a small number of variables appears to be consistently non-significant across all four regressions. Thus, if we took significance in at least one regression as the selection criterion, this would still leave us with a very large number of explanatory variables. Consequently, for each of the two currencies, we selected only those variables that appear to be significant both in the EUR and USD regression. Applying this criterion leads to a choice of 22 variables for the CHF and 25 variables for the JPY. Table A2 in the Appendix provides descriptive statistics for all these variables.

Tables 1 (for the CHF) and 2 (for the JPY) report detailed regression results using the explanatory variables we just selected. As the $p$ values show all coefficients appear to be highly significant. Generally speaking, as one might

Table 1 Full-sample estimates for the CHF

\begin{tabular}{|c|c|c|c|c|c|c|}
\hline \multicolumn{7}{|c|}{ Sample: $1 / 01 / 2000$ to $12 / 31 / 2013$} \\
\hline \multirow{3}{*}{ Dependent variable: $\Delta f x_{t+1}^{c}$} & \multicolumn{3}{|c|}{ Observations: 2388} & \multicolumn{3}{|c|}{ Observations: 2388} \\
\hline & \multicolumn{3}{|c|}{$c=E U R C H F$} & \multicolumn{3}{|c|}{$c=U S D C H F$} \\
\hline & $\beta_{k}$ & Std. error & $p$ value & $\beta_{k}$ & Std. error & $p$ value \\
\hline C & -0.002 & 0.001 & 0.215 & -0.001 & 0.002 & 0.555 \\
\hline$\Delta f x_{t}^{c}$ & -0.095 & 0.062 & 0.123 & -0.347 & 0.091 & 0.000 \\
\hline \multicolumn{7}{|l|}{ Swiss variables } \\
\hline Retail sales & -0.014 & 0.008 & 0.064 & -0.021 & 0.009 & 0.025 \\
\hline KOF barometer & -0.023 & 0.006 & 0.000 & -0.030 & 0.008 & 0.000 \\
\hline PMI & -0.022 & 0.004 & 0.000 & -0.020 & 0.006 & 0.001 \\
\hline Real GDP & -0.030 & 0.011 & 0.004 & -0.027 & 0.012 & 0.025 \\
\hline \multicolumn{7}{|l|}{ German variables } \\
\hline Real GDP & 0.021 & 0.005 & 0.000 & -0.035 & 0.009 & 0.000 \\
\hline IFO business climate & 0.014 & 0.004 & 0.000 & -0.063 & 0.011 & 0.000 \\
\hline Retail sales & 0.003 & 0.002 & 0.083 & -0.018 & 0.008 & 0.020 \\
\hline ZEW indicator & 0.013 & 0.003 & 0.000 & -0.032 & 0.007 & 0.000 \\
\hline \multicolumn{7}{|l|}{ US variables } \\
\hline Avg hourly earnings all & 0.054 & 0.032 & 0.092 & 0.089 & 0.037 & 0.018 \\
\hline Emp.st. busin. cond. index & 0.013 & 0.005 & 0.009 & 0.035 & 0.010 & 0.001 \\
\hline Consumer confidence & 0.021 & 0.004 & 0.000 & 0.036 & 0.011 & 0.001 \\
\hline Phifed curr. busin. cond. & 0.026 & 0.010 & 0.010 & 0.052 & 0.011 & 0.000 \\
\hline Employment non-farm & 0.052 & 0.015 & 0.001 & 0.241 & 0.039 & 0.000 \\
\hline Housing starts & 0.012 & 0.003 & 0.000 & 0.020 & 0.010 & 0.051 \\
\hline Industrial production & 0.012 & 0.005 & 0.012 & 0.022 & 0.009 & 0.013 \\
\hline ISM non-manuf. & 0.027 & 0.009 & 0.004 & 0.056 & 0.019 & 0.003 \\
\hline ISM manuf. & 0.045 & 0.015 & 0.003 & 0.083 & 0.015 & 0.000 \\
\hline New home sales & 0.013 & 0.004 & 0.001 & 0.041 & 0.009 & 0.000 \\
\hline New orders dur. goods & 0.012 & 0.005 & 0.008 & 0.045 & 0.012 & 0.000 \\
\hline Real GDP adv & 0.033 & 0.012 & 0.006 & 0.163 & 0.033 & 0.000 \\
\hline Real GDP final & 0.014 & 0.006 & 0.021 & 0.028 & 0.016 & 0.070 \\
\hline Unemployment rate & 0.030 & 0.011 & 0.009 & 0.074 & 0.027 & 0.006 \\
\hline$R^{2}$ & 0.152 & & & 0.291 & & \\
\hline Adjusted $R^{2}$ & 0.143 & & & 0.284 & & \\
\hline Prob(F-stat) & 0.000 & & & 0.000 & & \\
\hline
\end{tabular}


Table 2 Full-sample estimates for the JPY

\begin{tabular}{|c|c|c|c|c|c|c|}
\hline \multicolumn{7}{|c|}{ Sample: $1 / 01 / 2000$ to $12 / 31 / 2013$} \\
\hline \multirow{3}{*}{ Dependent variable: $\Delta f x_{t+1}^{c}$} & \multirow{2}{*}{\multicolumn{3}{|c|}{$\begin{array}{l}\text { Observations: } 2239 \\
c=\text { EURJPY }\end{array}$}} & \multirow{2}{*}{\multicolumn{3}{|c|}{$\begin{array}{l}\text { Observations: } 2239 \\
c=\text { USDJPY }\end{array}$}} \\
\hline & & & & & & \\
\hline & $\beta_{k}$ & Std. error & $p$ value & $\beta_{k}$ & Std. error & $p$ value \\
\hline C & 0.002 & 0.003 & 0.379 & 0.004 & 0.002 & 0.076 \\
\hline$\Delta f x_{t}^{c}$ & -0.162 & 0.072 & 0.024 & -0.285 & 0.069 & 0.000 \\
\hline \multicolumn{7}{|l|}{ Japanese variables } \\
\hline Machinery orders & -0.029 & 0.005 & 0.000 & -0.031 & 0.005 & 0.000 \\
\hline Retail sales & -0.008 & 0.005 & 0.097 & -0.008 & 0.004 & 0.057 \\
\hline Household expenditure & -0.009 & 0.004 & 0.021 & -0.008 & 0.004 & 0.052 \\
\hline Real GDP final & 0.022 & 0.006 & 0.000 & 0.020 & 0.005 & 0.000 \\
\hline \multicolumn{7}{|l|}{ Euro area variables } \\
\hline Business climate & 0.022 & 0.007 & 0.002 & 0.009 & 0.004 & 0.031 \\
\hline \multicolumn{7}{|l|}{ German variables } \\
\hline Retail sales & 0.029 & 0.014 & 0.042 & 0.011 & 0.004 & 0.012 \\
\hline \multicolumn{7}{|l|}{ US variables } \\
\hline Avg hourly earnings pro & 0.048 & 0.028 & 0.092 & 0.080 & 0.035 & 0.024 \\
\hline Emp.et. busin. cond. index & 0.019 & 0.010 & 0.066 & 0.046 & 0.012 & 0.000 \\
\hline Consumer confidence & 0.049 & 0.016 & 0.002 & 0.067 & 0.011 & 0.000 \\
\hline Phifed curr. busin. cond. & 0.044 & 0.011 & 0.000 & 0.066 & 0.010 & 0.000 \\
\hline Employment non-farm & 0.095 & 0.037 & 0.010 & 0.286 & 0.031 & 0.000 \\
\hline Existing home sales & 0.029 & 0.014 & 0.034 & 0.041 & 0.010 & 0.000 \\
\hline Housing starts & 0.016 & 0.006 & 0.004 & 0.024 & 0.010 & 0.011 \\
\hline Import goods and serv. & 0.03 & 0.012 & 0.017 & -0.054 & 0.017 & 0.001 \\
\hline Industrial production & 0.016 & 0.006 & 0.012 & 0.026 & 0.006 & 0.000 \\
\hline ISM non-manuf. & 0.044 & 0.017 & 0.009 & 0.073 & 0.018 & 0.000 \\
\hline ISM manuf. & 0.063 & 0.017 & 0.000 & 0.103 & 0.013 & 0.000 \\
\hline Comp.index leading ind. & 0.021 & 0.010 & 0.031 & 0.028 & 0.007 & 0.000 \\
\hline New orders dur. goods & 0.017 & 0.009 & 0.064 & 0.052 & 0.011 & 0.000 \\
\hline Productivity & 0.026 & 0.015 & 0.079 & 0.028 & 0.006 & 0.000 \\
\hline Retail sales & 0.060 & 0.016 & 0.000 & 0.09 & 0.014 & 0.000 \\
\hline Real GDP final & 0.032 & 0.011 & 0.005 & 0.049 & 0.015 & 0.001 \\
\hline Real GDP pre & 0.031 & 0.016 & 0.050 & 0.066 & 0.014 & 0.000 \\
\hline Unit labor costs & 0.041 & 0.021 & 0.052 & 0.025 & 0.004 & 0.000 \\
\hline Unemployment rate & 0.070 & 0.028 & 0.012 & 0.109 & 0.025 & 0.000 \\
\hline$R^{2}$ & \multicolumn{3}{|l|}{0.107} & \multicolumn{3}{|l|}{0.345} \\
\hline Adjusted $R^{2}$ & \multicolumn{3}{|l|}{0.096} & \multicolumn{3}{|l|}{0.336} \\
\hline $\operatorname{Prob}(F$-stat) & \multicolumn{3}{|l|}{0.000} & \multicolumn{3}{|l|}{0.000} \\
\hline
\end{tabular}

have expected, returns in both currencies are strongly affected by US macroeconomic surprises. However, the exposure to US macroeconomic surprises is more pronounced for the JPY than for the CHF: 19 US variables impact the JPY crosses, against 14 variables for the CHF.
European news is more relevant for the CHF: four variables enter the CHF regressions, while only two are relevant for the JPY crosses. In the case of the CHF, only German variables have been selected, while in the case of the JPY, one euro area-wide variable emerges. All in 
all, there thus seems to be surprisingly little systematic impact of non-German European variables on the two currencies.

A further interesting result concerns domestic indicators. Both currencies are significantly impacted by surprises in their domestic macroeconomic variables. Hence, movements in the CHF and the JPY are not driven only by international macroeconomic surprises. Unexpected domestic developments do matter.

All in all, the $R^{2}$ metric tells us that in this baseline specification our regressions explain between $15 \%$ and $29 \%$ in the variation of 5 min returns for the CHF and between $11 \%$ and $35 \%$ for the JPY returns. As a comparison, the highest $R^{2}$ obtained by Ranaldo and Söderlind (2010) is 8\% (for USDCHF). This suggests that macroeconomic surprises are important independent drivers of safe-haven currencies.

Looking at the EURCHF cross, all foreign variables display a positive sign. This corresponds to the expected result. It implies that positive surprises $\left(S_{k}>0\right)$ favor a depreciation of the CHF vs the EUR ${ }^{5}$. Conversely, negative surprises $\left(S_{k}<0\right)$ lead to an appreciation of the CHF. Domestic variables bear a negative sign. This is again the result we expected. Positive domestic surprises naturally tend to generate an appreciation pressure as they ceteris paribus imply a risk of a tighter monetary policy than previously projected. As far as the USDCHF regression is concerned, results are similar, with one prominent exception: all German variables are significant but bear the wrong sign. The explanation is to be found via the EURUSD cross. Positive German surprises cause an appreciation of the EUR against the USD and the CHF. The former being more pronounced than the latter, the Swiss currency appreciates against the USD. Results for the JPY are qualitatively very similar. Most $\beta_{k}$ coefficients are highly significant and only one bears the wrong sign.

\subsection{What about other currencies?}

In a next step, we prove that these results are specific to the CHF and the JPY. In order to do that, we extend our analysis of the impact of macroeconomic surprises to three additional currencies: the Australian Dollar (AUD), the Canadian Dollar (CAD), and the British Pound (GBP). As EBS is not a relevant trading platform for these currencies, we took the corresponding 5-min exchange rate series from HistData.com, a freely available datasource.

As for EURCAD, the time series is too short, we end up running regressions for EURAUD, USDAUD, EURGBP, USDGBP, and USDCAD. As regressors, we use all foreign macroeconomic surprises that turned out to be important for either the CHF or the JPY, 26 variables in total ${ }^{6}$.

Results are shown in Table A1 in the Appendix. For the AUD, CAD, or GBP to display similar properties as the JPY or the CHF, the estimated coefficients should be invariably positive. The estimated constant and autoregressive coefficient are not reported in the Table. The number of coefficients that turns out to be significant is small. It ranges between three (for USDGBP) and seven (for EURGBP). In addition, these coefficients bear either a positive or a negative sign in roughly equal proportions. As a consequence, no proper pattern emerges.

Figures 4 and 5 make a direct comparison of the estimated coefficients for our two safe-haven currencies and these other currencies. The black stars mark the range of the estimated coefficients for the AUD, CAD, and GBP from Table A1. The red and grey diamonds and the corresponding whiskers show the coefficients' estimates and their confidence intervals for the CHF (Fig. 4) and the JPY (Fig. 5). The two figures make rapidly apparent that the coefficients tend to be systematically larger in the case of the CHF and JPY. In many instances, there is not even an overlap between the CHF and JPY confidence intervals, on the one hand, and the range of estimated coefficients for the other crosses, on the other. We conclude that the high and broad-based sensitivity of the JPY and CHF to macroeconomic surprises is a specificity of safe-haven currencies.

\subsection{Impact of the crisis}

Next, we want to check whether the crisis has impacted the link between macroeconomic surprises and $\mathrm{CHF}$ or JPY variations. The hypothesis is that, in periods of heightened uncertainty, safe-haven currencies react more to macroeconomic surprises. As a divide, we take the outbreak of the subprime crisis in August 2007. Figure 1 shows that both currencies initiated an appreciation trend precisely around this time. Tables 3 and 4 show regression results. To make the main result easier to spot, coefficients of variables that are more relevant in the second period are in bold print.

In three out of four crosses, the number of coefficients that turns out to be significant is substantially larger in the second period. The exception is provided by the USDCHF cross. Interestingly, it is only in terms of foreign variables that a pattern emerges between the two subsamples. In other words, there is no obvious evidence that the role of domestic variables varies in the two periods.

It is not just the number of significant coefficients for foreign variables that changes, but also the size of these coefficients. Typically, these are several orders of magnitude bigger during the crisis than in the pre-crisis period. For instance, whereas the reaction of EURCHF to surprises in the German real GDP is twice as big and the reaction to surprises in the US Empire State Business Conditions Index or in the Consumer Confidence is some four times larger, the reaction to surprises in the US non-manufacturing ISM is no less than 20 times larger. In the case of the JPY, the change between the 


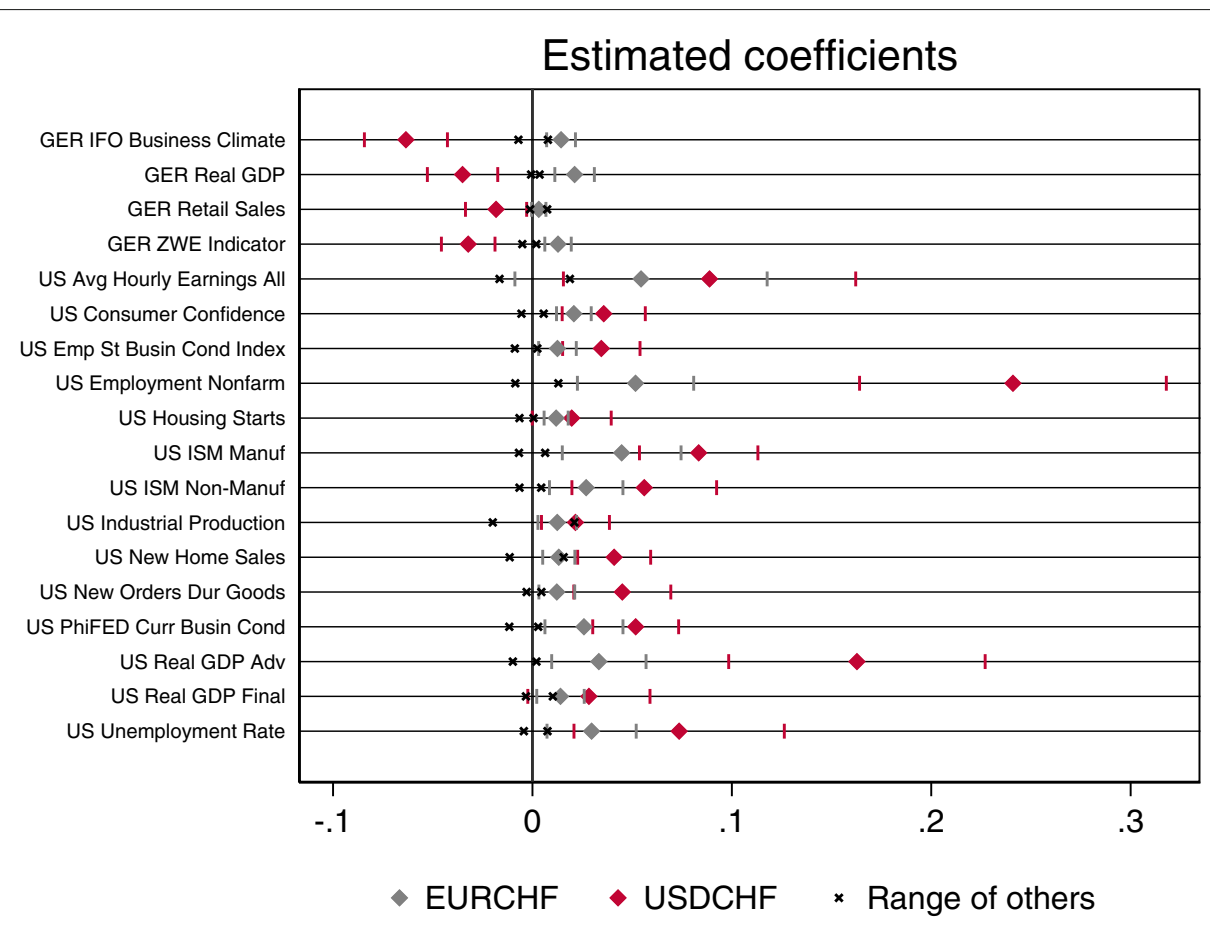

Fig. 4 Coefficients' estimates-CHF vs. AUD, CAD , and GBP

two periods is extremely impressive. Whereas domestic surprises tend to be significant (and bear the right sign) already in the pre-crisis period, most foreign variables turn significant only when the crisis occurs. This pattern is clearly visible in both the EURJPY and USDJPY exchange rates. The most extreme individual case is provided by surprises in the non-farm payroll measure of employment: while in the pre-crisis period this variable bears the wrong sign, in the crisis a one standard deviation negative surprise generated a $0.27 \%$ JPY appreciation against the EUR and a $0.37 \%$ appreciation against the USD.

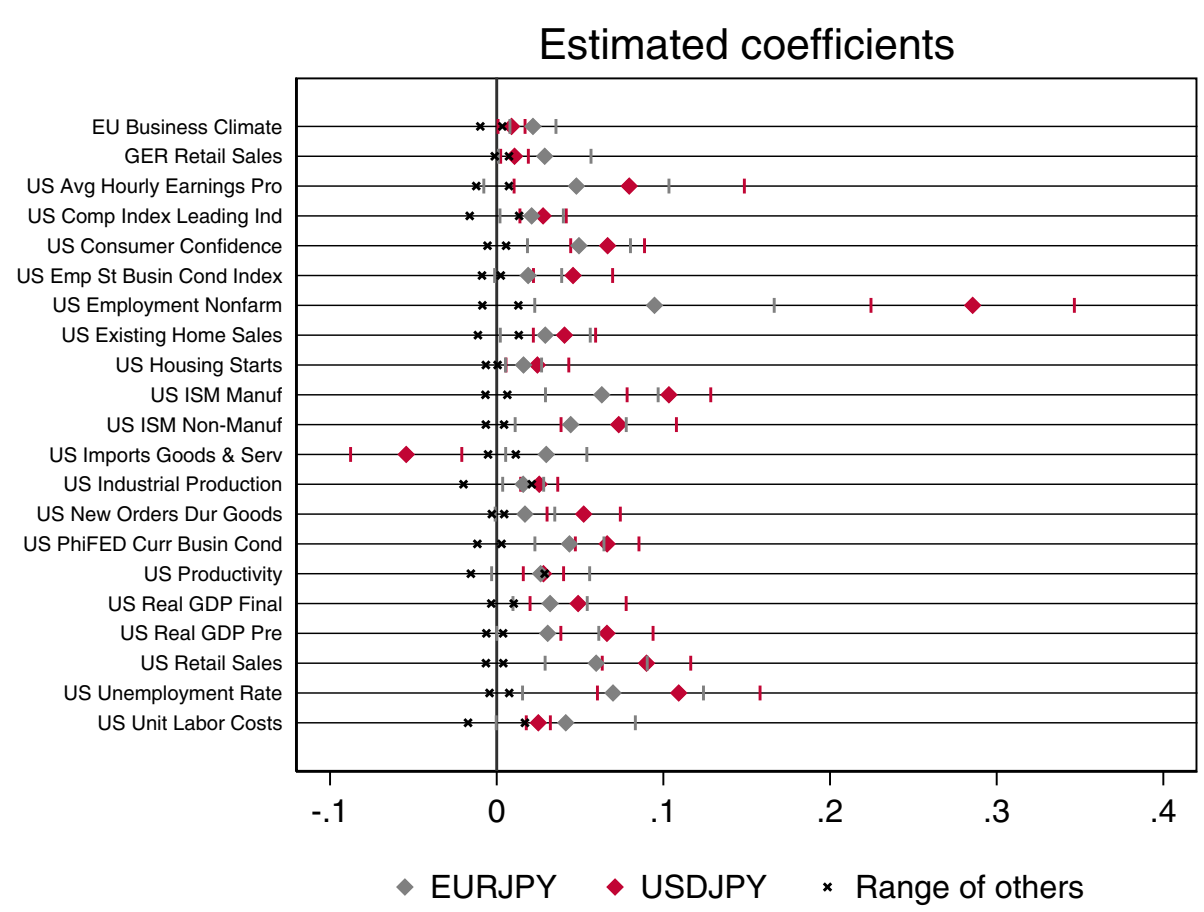

Fig. 5 Coefficients' estimates_JPY vs. AUD, CAD, and GBP 
Table 3 Crisis vs. pre-crisis for the CHF

\begin{tabular}{|c|c|c|c|c|c|c|c|c|}
\hline \multicolumn{9}{|c|}{ Pre-crisis sample: $1 / 01 / 2000$ to $7 / 31 / 2007$; crisis sample: $8 / 01 / 2007$ to $12 / 31 / 2013$} \\
\hline & \multicolumn{2}{|c|}{ Pre-crisis } & \multicolumn{2}{|c|}{ Crisis } & \multicolumn{2}{|c|}{ Pre-crisis } & \multicolumn{2}{|c|}{ Crisis } \\
\hline & \multicolumn{2}{|c|}{ Obs: 1051} & \multicolumn{2}{|c|}{ Obs: 1337} & \multicolumn{2}{|c|}{ Obs: 1051} & \multicolumn{2}{|c|}{ Obs: 1337} \\
\hline \multirow[t]{2}{*}{ Dependent variable: $\Delta f x_{t+1}^{c}$} & \multicolumn{2}{|c|}{$c=E U R C H F$} & \multicolumn{2}{|c|}{$c=E U R C H F$} & \multicolumn{2}{|c|}{$c=U S D C H F$} & \multicolumn{2}{|c|}{$c=U S D C H F$} \\
\hline & $\beta_{k}$ & $p$ value & $\beta_{k}$ & $p$ value & $\beta_{k}$ & $p$ value & $\beta_{k}$ & $p$ value \\
\hline C & -0.001 & 0.100 & -0.002 & 0.418 & 0.001 & 0.733 & -0.003 & 0.364 \\
\hline$\Delta f x_{t}^{c}$ & -0.155 & 0.008 & -0.117 & 0.105 & -0.484 & 0.001 & -0.285 & 0.006 \\
\hline \multicolumn{9}{|l|}{ Swiss variables } \\
\hline Retail sales & 0.007 & 0.040 & -0.021 & 0.016 & -0.030 & 0.000 & -0.018 & 0.095 \\
\hline KOF barometer & -0.044 & 0.007 & -0.010 & 0.056 & -0.050 & 0.008 & -0.015 & 0.061 \\
\hline PMl & -0.003 & 0.483 & -0.028 & 0.000 & -0.005 & 0.358 & -0.025 & 0.001 \\
\hline Real GDP & -0.060 & 0.000 & -0.024 & 0.034 & -0.063 & 0.000 & -0.019 & 0.111 \\
\hline \multicolumn{9}{|l|}{ German variables } \\
\hline Real GDP & 0.009 & 0.034 & 0.025 & 0.000 & -0.017 & 0.207 & -0.040 & 0.000 \\
\hline IFO business climate & 0.010 & 0.000 & 0.018 & 0.003 & -0.077 & 0.000 & -0.054 & 0.000 \\
\hline Retail sales & 0.002 & 0.400 & 0.007 & 0.054 & -0.022 & 0.045 & -0.010 & 0.121 \\
\hline Zew indicator & 0.005 & 0.035 & 0.020 & 0.001 & -0.028 & 0.006 & -0.036 & 0.000 \\
\hline \multicolumn{9}{|l|}{ US variables } \\
\hline Avg hourly earnings all & & & 0.052 & 0.090 & & & 0.092 & 0.021 \\
\hline Emp.st. busin. cond. index & 0.004 & 0.083 & 0.017 & 0.020 & 0.050 & 0.000 & 0.026 & 0.053 \\
\hline Consumer confidence & 0.007 & 0.023 & 0.028 & 0.000 & 0.094 & 0.000 & 0.007 & 0.521 \\
\hline Phifed curr. busin.cond. & 0.000 & 0.961 & 0.035 & 0.005 & 0.061 & 0.001 & 0.049 & 0.000 \\
\hline Employment non-farm & 0.016 & 0.025 & 0.090 & 0.001 & 0.292 & 0.000 & 0.188 & 0.000 \\
\hline Housing starts & 0.004 & 0.028 & 0.029 & 0.001 & 0.012 & 0.226 & 0.035 & 0.180 \\
\hline Industrial production & 0.003 & 0.274 & 0.016 & 0.016 & 0.043 & 0.002 & 0.015 & 0.131 \\
\hline ISM non-manuf. & & & 0.027 & 0.044 & & & 0.056 & 0.002 \\
\hline ISM manuf. & 0.005 & 0.046 & 0.08 & 0.002 & 0.074 & 0.000 & 0.092 & 0.000 \\
\hline New home sales & 0.011 & 0.000 & 0.027 & 0.094 & 0.037 & 0.000 & 0.038 & 0.248 \\
\hline New orders dur. goods & 0.004 & 0.321 & 0.019 & 0.019 & 0.069 & 0.000 & 0.027 & 0.079 \\
\hline Real GDP adv & 0.013 & 0.038 & 0.050 & 0.015 & 0.232 & 0.000 & 0.108 & 0.003 \\
\hline Real GDP final & -0.001 & 0.879 & 0.019 & 0.017 & 0.037 & 0.175 & 0.027 & 0.123 \\
\hline Unemployment rate & 0.005 & 0.490 & 0.035 & 0.013 & 0.099 & 0.046 & 0.067 & 0.034 \\
\hline$R^{2}$ & 0.205 & & 0.209 & & 0.407 & & 0.224 & \\
\hline Adjusted $R^{2}$ & 0.188 & & 0.194 & & 0.394 & & 0.209 & \\
\hline Prob(F-stat) & 0.000 & & 0.000 & & 0.000 & & 0.000 & \\
\hline
\end{tabular}

All in all, we thus find strong evidence of a much more pronounced impact of foreign macroeconomic surprises on our two safe-haven currencies during the recent crisis. The increased impact of macroeconomic surprises is also reflected in higher $R^{2}$ in the crisis. These results complement the evidence in Goldberg and Grisse (2013) on time-varying responses of asset prices to macroeconomic surprises.

In a separate set of regressions we look at whether macroeconomic surprises also have more persistent effects in the crisis, by using one to several hour windows instead of a 5-min window to compute the change in the exchange rates. We find no evidence of a change in patterns in this respect. This result stands in no contradiction to the increased intensity of reaction in 5-min windows, as of course the crisis is a time of much higher volatility in exchange rates.

\subsection{Asymmetries}

One open question is whether safe-haven currencies respond symmetrically to macroeconomic surprises. Evidence in this respect diverges. Fatum et al. (2012) inves- 
Table 4 Crisis vs. pre-crisis for the JPY

\begin{tabular}{|c|c|c|c|c|c|c|c|c|}
\hline \multicolumn{9}{|c|}{ Pre-crisis sample: $1 / 01 / 2000$ to $7 / 31 / 2007$; crisis sample: $8 / 01 / 2007$ to $12 / 31 / 2013$} \\
\hline & \multicolumn{2}{|c|}{ Pre-crisis } & \multicolumn{2}{|c|}{ Crisis } & \multicolumn{2}{|c|}{ Pre-crisis } & \multicolumn{2}{|c|}{ Crisis } \\
\hline & \multicolumn{2}{|c|}{ Obs: 991} & \multicolumn{2}{|c|}{ Obs: 1248} & \multicolumn{2}{|c|}{ Obs: 991} & \multicolumn{2}{|c|}{ Obs: 1248} \\
\hline \multirow[t]{2}{*}{ Dependent variable: $\Delta f x_{t+1}^{c}$} & \multicolumn{2}{|c|}{$c=E U R J P Y$} & \multicolumn{2}{|c|}{$c=$ EURJPY } & \multicolumn{2}{|c|}{$c=$ USDJPY } & \multicolumn{2}{|c|}{$c=$ USDJPY } \\
\hline & $\beta_{k}$ & $p$ value & $\beta_{k}$ & $p$ value & $\beta_{k}$ & $p$ value & $\beta_{k}$ & $p$ value \\
\hline C & 0.001 & 0.835 & 0.006 & 0.142 & 0.000 & 0.881 & 0.008 & 0.030 \\
\hline$\Delta f x_{t}^{c}$ & -0.315 & 0.000 & -0.203 & 0.016 & -0.162 & 0.072 & -0.349 & 0.000 \\
\hline \multicolumn{9}{|l|}{ Japanese variables } \\
\hline Machinery orders & -.054 & 0.000 & -0.018 & 0.003 & -0.063 & 0.000 & -0.018 & 0.000 \\
\hline Retail sales & -0.023 & 0.049 & -0.003 & 0.558 & -0.029 & 0.028 & -0.002 & 0.689 \\
\hline Household expenditures & -0.008 & 0.208 & -0.010 & 0.042 & -0.013 & 0.151 & -0.007 & 0.119 \\
\hline Real GDP final & -0.074 & 0.040 & 0.026 & 0.000 & -0.073 & 0.000 & 0.024 & 0.000 \\
\hline \multicolumn{9}{|l|}{ Euro area variables } \\
\hline Business climate & 0.010 & 0.133 & 0.032 & 0.008 & 0.006 & 0.310 & 0.012 & 0.042 \\
\hline \multicolumn{9}{|l|}{ German variables } \\
\hline Retail sales & 0.030 & 0.147 & 0.032 & 0.003 & 0.008 & 0.164 & 0.015 & 0.026 \\
\hline \multicolumn{9}{|l|}{ US variables } \\
\hline Avg hourly earnings pro & 0.017 & 0.461 & 0.097 & 0.242 & 0.063 & 0.060 & 0.082 & 0.358 \\
\hline Emp.st. busin. cond. index & -0.019 & 0.009 & 0.040 & 0.008 & 0.031 & 0.012 & 0.055 & 0.001 \\
\hline Consumer confidence & -0.035 & 0.000 & 0.093 & 0.000 & 0.053 & 0.001 & 0.075 & 0.000 \\
\hline Phifed curr. busin. cond. & -0.032 & 0.014 & 0.071 & 0.000 & 0.024 & 0.011 & 0.082 & 0.000 \\
\hline Employment non-farm & -0.077 & 0.006 & 0.271 & 0.000 & 0.199 & 0.000 & 0.366 & 0.000 \\
\hline Existing home sales & 0.003 & 0.651 & 0.044 & 0.063 & 0.029 & 0.020 & 0.047 & 0.001 \\
\hline Housing starts & 0.002 & 0.732 & 0.048 & 0.002 & 0.010 & 0.239 & 0.060 & 0.049 \\
\hline Import goods and serv. & 0.035 & 0.008 & 0.020 & 0.411 & -0.082 & 0.000 & 0.000 & 0.995 \\
\hline Industrial production & -0.006 & 0.481 & 0.024 & 0.002 & 0.030 & 0.003 & 0.026 & 0.000 \\
\hline ISM non-manuf. & & & 0.044 & 0.009 & & & 0.073 & 0.000 \\
\hline ISM manuf. & -0.013 & 0.266 & 0.130 & 0.000 & 0.052 & 0.000 & 0.147 & 0.000 \\
\hline Comp.index leading ind. & -0.003 & 0.569 & 0.034 & 0.012 & 0.006 & 0.286 & 0.039 & 0.000 \\
\hline New orders dur. goods & -0.015 & 0.013 & 0.042 & 0.004 & 0.049 & 0.000 & 0.053 & 0.004 \\
\hline Productivity & 0.032 & 0.269 & 0.025 & 0.143 & 0.009 & 0.556 & 0.033 & 0.000 \\
\hline Retail sales & -0.019 & 0.029 & 0.105 & 0.000 & 0.061 & 0.000 & 0.107 & 0.000 \\
\hline Real GDP final & -0.015 & 0.224 & 0.046 & 0.001 & 0.021 & 0.291 & 0.061 & 0.001 \\
\hline Real GDP pre & 0.002 & 0.847 & 0.042 & 0.050 & 0.022 & 0.201 & 0.084 & 0.000 \\
\hline Unit labor costs & -0.015 & 0.659 & 0.045 & 0.033 & 0.008 & 0.770 & 0.028 & 0.000 \\
\hline Unemployment rate & 0.007 & 0.806 & 0.090 & 0.010 & 0.109 & 0.003 & 0.117 & 0.000 \\
\hline$R^{2}$ & 0.155 & & 0.286 & & 0.350 & & 0.395 & \\
\hline Adjusted $R^{2}$ & 0.131 & & 0.269 & & 0.332 & & 0.381 & \\
\hline $\operatorname{Prob}(F$-stat) & 0.000 & & 0.000 & & 0.000 & & 0.000 & \\
\hline
\end{tabular}

tigate this issue for the USDJPY over the 1999-2006 period. They conclude that negative US macroeconomic surprises have somewhat larger effects than positive surprises. Pearce and Solakoglu (2007) argue on the contrary that no evidence of asymmetric reactions can be found in the dollar-deutsche mark and the dollar-yen exchange rates. They use data spanning between 1986 and 1996 and surprises for a much smaller number of variables than we do here.

We collected all surprises that have the potential to generate an appreciation in an APP_ $S_{t}$ vector and all surprises potentially leading to a depreciation in a DEP_ $S_{t}$ vector. Hence, in the case of the EURCHF for instance, $\mathrm{APP} S_{t}$ contains all negative foreign surprises as well as 
the domestic positive surprises, multiplied by -1 . DEP_ $S_{t}$ contains all positive foreign surprises and all negative domestic surprises, again with the inverted sign. We then estimate the following regression for the pre-crisis and the crisis samples:

$$
\Delta f x_{t+1}^{c}=\alpha^{c}+\Delta f x_{t}^{c}+\beta_{a} \mathrm{APP} \_S_{t}+\beta_{d} \mathrm{DEP} \_S_{t}+\varepsilon_{t}^{c} .
$$

We expect both $\beta_{a}$ and $\beta_{d}$ to have a positive sign. Asymmetry would request $\beta_{a} \neq \beta_{d}$. Table 5 displays the results.

In all but one case, coefficients bear the expected sign. Whereas in the pre-crisis sample no clear pattern emerges, in the crisis period the coefficient of APP_ $S_{t}$ is larger than the DEP_S $S_{t}$ coefficient in all four regressions. This suggests that macroeconomic surprises have a somewhat larger impact on both currencies when they induce an appreciation than when they have weakening effects. However, $t$ tests do not allow for a formal rejection of the the $\beta_{a}=\beta_{d}$ hypothesis. We should recall that the crisis sample also contains extended periods in which monetary policy counteracted appreciation tendencies in the two currencies. Still, we interpret these results as a signal that to some degree asymmetric reactions might be at work, adding evidence to the findings of Fatum et al. (2012).

Note also that this parsimonious specification confirms the qualitative results of Tables 3 and 4: the surprise coefficients tend to be larger and the $R^{2}$ higher in the crisis period than in the pre-crisis period. The only exception is again the USDCHF cross.

\subsection{Non-linearity}

Ranaldo and Söderlind suggest that safe-haven currencies may behave in a non-linear fashion. In particular, they seem to respond non-linearly to varying levels of their preferred risk measure, observed volatility in the FX markets. In the following step, we analyze whether evidence of non-linear responses to macroeconomic surprises can be found. We estimate the following regressions

$$
\Delta f x_{t+1}^{c}=\alpha^{c}+\Delta f x_{t}^{c}+\beta_{a} \mathrm{APP} \_S_{t}+\beta_{a a}\left(A P P \_S_{t}\right)^{2}+\varepsilon_{t}^{c}
$$

$$
\Delta f x_{t+1}^{c}=\alpha^{c}+\Delta f x_{t}^{c}+\beta_{d} \mathrm{DEP} \_S_{t}+\beta_{d d}\left(D E P \_S_{t}\right)^{2}+\varepsilon_{t}^{c}
$$

The non-linearity hypothesis is confirmed if $\beta_{a a}<0$ and $\beta_{d d}>0$. As results in Table 6 show, we find no evidence at all of a non-linear impact of large surprises.

\subsection{Impact of the monetary policy regime}

One might wonder to what extent the link between macroeconomic surprises and exchange rate reactions is affected by the attitude of monetary authorities. In a further step, we therefore investigate whether the sensitivity of the CHF and the JPY to macroeconomic surprises was modified by the change in the SNB and BoJ monetary policy regimes. The landmarks are provided by the adoption of the minimum-exchange-rate policy by the SNB in September 2011 and by the implementation of a more aggressive quantitative-easing policy by the BoJ as of

\begin{tabular}{|c|c|c|c|c|c|c|c|c|}
\hline \multicolumn{9}{|c|}{ Pre-crisis sample: 1/01/2000 to 07/31/2007 } \\
\hline \multirow{3}{*}{ Dependent variable: $\Delta f x_{t+1}^{c}$} & \multirow{2}{*}{\multicolumn{2}{|c|}{$\begin{array}{c}\text { Obs: } 1051 \\
c=\text { EURCHF }\end{array}$}} & \multirow{2}{*}{\multicolumn{2}{|c|}{$\begin{array}{l}\text { Obs: } 1051 \\
c=\text { USDCHF }\end{array}$}} & \multirow{2}{*}{\multicolumn{2}{|c|}{$\begin{array}{l}\text { Obs: } 991 \\
c=\text { EURJPY }\end{array}$}} & \multirow{2}{*}{\multicolumn{2}{|c|}{$\begin{array}{l}\text { Obs: } 991 \\
c=\text { USDJPY }\end{array}$}} \\
\hline & & & & & & & & \\
\hline & $\beta_{k}$ & $p$ value & $\beta_{k}$ & $p$ value & $\beta_{k}$ & $p$ value & $\beta_{k}$ & $p$ value \\
\hline C & -0.001 & 0.605 & -0.007 & 0.178 & 0.002 & 0.653 & 0.005 & 0.283 \\
\hline$\Delta f x_{t}^{c}$ & -0.141 & 0.009 & -0.346 & 0.088 & -0.262 & 0.002 & -0.054 & 0.679 \\
\hline APP_S $S_{t}$ & 0.008 & 0.000 & 0.056 & 0.000 & -0.003 & 0.558 & 0.047 & 0.000 \\
\hline DEP_S $S_{t}$ & 0.006 & 0.000 & 0.063 & 0.000 & -0.003 & 0.699 & 0.030 & 0.000 \\
\hline$R^{2}$ & 0.073 & & 0.174 & & 0.017 & & 0.133 & \\
\hline Adjusted $R^{2}$ & 0.071 & & 0.171 & & 0.014 & & 0.130 & \\
\hline \multicolumn{9}{|c|}{ Crisis sample: $8 / 01 / 2007$ to $12 / 31 / 2013$} \\
\hline \multirow{3}{*}{ Dependent variable: $\Delta f x_{t+1}^{c}$} & \multirow{2}{*}{\multicolumn{2}{|c|}{$\begin{array}{c}\text { Obs: } 1337 \\
c=\text { EURCHF }\end{array}$}} & \multirow{2}{*}{\multicolumn{2}{|c|}{$\begin{array}{l}\text { Obs: } 1337 \\
c=\text { USDCHF }\end{array}$}} & \multirow{2}{*}{\multicolumn{2}{|c|}{$\begin{array}{l}\text { Obs: } 1248 \\
c=\text { EURJPY }\end{array}$}} & \multirow{2}{*}{\multicolumn{2}{|c|}{$\begin{array}{l}\text { Obs: } 1248 \\
c=\text { USDJPY }\end{array}$}} \\
\hline & & & & & & & & \\
\hline & $\beta_{k}$ & $p$ value & $\beta_{k}$ & $p$ value & $\beta_{k}$ & $p$ value & $\beta_{k}$ & $p$ value \\
\hline C & 0.004 & 0.227 & -0.001 & 0.906 & 0.009 & 0.228 & 0.009 & 0.182 \\
\hline$\Delta f x_{t}^{c}$ & -0.108 & 0.131 & -0.283 & 0.009 & -0.172 & 0.059 & -0.254 & 0.031 \\
\hline APP_S $S_{t}$ & 0.034 & 0.000 & 0.048 & 0.000 & 0.053 & 0.000 & 0.060 & 0.000 \\
\hline DEP_S & 0.021 & 0.000 & 0.039 & 0.000 & 0.044 & 0.000 & 0.055 & 0.000 \\
\hline$R^{2}$ & 0.137 & & 0.129 & & 0.126 & & 0.159 & \\
\hline Adjusted $R^{2}$ & 0.135 & & 0.128 & & 0.124 & & 0.157 & \\
\hline
\end{tabular}
December 2012.

Table 5 Asymmetries 
Table 6 Non-linearity

\begin{tabular}{|c|c|c|c|c|c|c|c|c|}
\hline \multicolumn{9}{|c|}{ Sample: $1 / 01 / 2000$ to $07 / 31 / 2007$} \\
\hline \multirow{3}{*}{ Dependent variable: $\Delta f x_{t+1}^{c}$} & \multirow{2}{*}{\multicolumn{2}{|c|}{$\begin{array}{l}\text { Obs: } 1173 \\
c=\text { EURCHF }\end{array}$}} & \multirow{2}{*}{\multicolumn{2}{|c|}{$\begin{array}{l}\text { Obs: } 1163 \\
c=\text { USDCHF }\end{array}$}} & \multirow{2}{*}{\multicolumn{2}{|c|}{$\begin{array}{l}\text { Obs: } 671 \\
c=\text { EURJPY }\end{array}$}} & \multirow{2}{*}{\multicolumn{2}{|c|}{$\begin{array}{l}\text { Obs: } 669 \\
c=\text { USDJPY }\end{array}$}} \\
\hline & & & & & & & & \\
\hline & $\beta_{k}$ & $p$ value & $\beta_{k}$ & $p$ value & $\beta_{k}$ & $p$ value & $\beta_{k}$ & $p$ value \\
\hline C & 0.001 & 0.631 & -0.010 & 0.408 & 0.010 & 0.389 & -0.019 & 0.165 \\
\hline$\Delta f x_{t}^{c}$ & -0.060 & 0.409 & 0.044 & 0.833 & -0.396 & 0.004 & -0.199 & 0.509 \\
\hline APP_S $S_{t}$ & 0.020 & 0.000 & 0.072 & 0.002 & -0.001 & 0.945 & 0.003 & 0.860 \\
\hline \multirow[t]{3}{*}{ SQR(APP_S $\left.S_{t}\right)$} & 0.005 & 0.000 & 0.010 & 0.143 & 0.001 & 0.629 & -0.016 & 0.000 \\
\hline & \multicolumn{2}{|c|}{$\begin{array}{l}\text { Obs: } 1087 \\
\text { c= EURCHF }\end{array}$} & \multicolumn{2}{|c|}{$\begin{array}{l}\text { Obs: } 1097 \\
c=\text { USDCHF }\end{array}$} & \multicolumn{2}{|c|}{$\begin{array}{c}\text { Obs: } 623 \\
c=\text { EURJPY }\end{array}$} & \multicolumn{2}{|c|}{$\begin{array}{c}\text { Obs: } 618 \\
c=\text { USDJPY }\end{array}$} \\
\hline & $\beta_{k}$ & $p$ value & $\beta_{k}$ & $p$ value & $\beta_{k}$ & $p$ value & $\beta_{k}$ & $p$ value \\
\hline C & 0.001 & 0.555 & -0.008 & 0.513 & -0.002 & 0.834 & -0.019 & 0.165 \\
\hline$\Delta f x_{t}^{c}$ & -0.205 & 0.024 & -0.698 & 0.023 & -0.273 & 0.158 & -0.377 & 0.072 \\
\hline DEP_S & 0.008 & 0.068 & 0.081 & 0.000 & -0.024 & 0.301 & 0.087 & 0.001 \\
\hline SQR(DEP_S $)$ & -0.001 & 0.360 & -0.009 & 0.203 & 0.007 & 0.563 & -0.001 & 0.153 \\
\hline \multicolumn{9}{|c|}{ Crisis sample: $8 / 01 / 2007$ to $12 / 31 / 2013$} \\
\hline \multirow{3}{*}{ Dependent variable: $\Delta f x_{t+1}^{c}$} & \multicolumn{2}{|c|}{ Obs: 682} & \multicolumn{2}{|c|}{ Obs: 679} & \multicolumn{2}{|c|}{ Obs: 397} & \multicolumn{2}{|c|}{ Obs: 395} \\
\hline & \multicolumn{2}{|c|}{$c=E U R C H F$} & \multicolumn{2}{|c|}{$c=U S D C H F$} & \multicolumn{2}{|c|}{$c=$ EURJPY } & \multicolumn{2}{|c|}{$c=$ USDJPY } \\
\hline & $\beta_{k}$ & $p$ value & $\beta_{k}$ & $p$ value & $\beta_{k}$ & $p$ value & $\beta_{k}$ & $p$ value \\
\hline C & 0.006 & 0.299 & 0.007 & 0.403 & 0.045 & 0.016 & 0.046 & 0.021 \\
\hline$\Delta f x_{t}^{c}$ & -0.065 & 0.574 & -0.340 & 0.041 & -0.240 & 0.131 & -0.440 & 0.028 \\
\hline APP_S $S_{t}$ & 0.034 & 0.013 & 0.068 & 0.000 & 0.159 & 0.000 & 0.184 & 0.000 \\
\hline \multirow[t]{3}{*}{$\operatorname{SQR}\left(\mathrm{APP}_{-} S_{t}\right)$} & 0.000 & 0.928 & 0.007 & 0.251 & 0.030 & 0.003 & 0.035 & 0.000 \\
\hline & \multicolumn{2}{|c|}{$\begin{array}{c}\text { Obs: } 611 \\
c=\text { EURCHF }\end{array}$} & \multicolumn{2}{|c|}{$\begin{array}{c}\text { Obs: } 614 \\
c=\text { USDCHF }\end{array}$} & \multicolumn{2}{|c|}{$\begin{array}{c}\text { Obs: } 357 \\
c=\text { EURJPY }\end{array}$} & \multicolumn{2}{|c|}{$\begin{array}{c}\text { Obs: } 352 \\
c=\text { USDJPY }\end{array}$} \\
\hline & $\beta_{k}$ & $p$ value & $\beta_{k}$ & $p$ value & $\beta_{k}$ & $p$ value & $\beta_{k}$ & $p$ value \\
\hline C & -0.007 & 0.103 & -0.019 & 0.030 & 0.034 & 0.076 & 0.033 & 0.075 \\
\hline$\Delta f x_{t}^{c}$ & -0.180 & 0.022 & -0.270 & 0.060 & -0.139 & 0.434 & -0.215 & 0.346 \\
\hline DEP_S $S_{t}$ & 0.043 & 0.000 & 0.087 & 0.000 & 0.015 & 0.618 & 0.044 & 0.143 \\
\hline SQR(DEP_S $\left.S_{t}\right)$ & -0.007 & 0.029 & -0.018 & 0.000 & 0.008 & 0.275 & 0.002 & 0.805 \\
\hline
\end{tabular}

Because of the reduced number of observations in the sample, we refer again to the parsimonious specification (3). Results are displayed in Table 7 and shall be compared to those in the lower panel of Table 5 .

If one is looking for nuances, then one might read estimates in Table 7 as suggesting that the size of the APP_S $S_{t}$ coefficients declined after the new policy regimes were adopted, particularly in the case of EURCHF and EURJPY. Globally, however, coefficients remain highly significant, suggesting an unchanged relevance of macroeconomic surprises. We thus conclude that macroeconomic surprises maintained their impact on the CHF and JPY even under these two specific policy regimes.

\subsection{Role of the market environment}

In a next step, we introduce the variables measuring general market conditions. We regress our four exchange rate crosses on all variables of Tables 1 and 2 respectively plus our daily market-environment measures $\mathrm{ME}_{t} \cdot \mathrm{ME}_{t}$ is alternatively measured by $\mathrm{VIX}_{t}$ and $\mathrm{BB}_{t}$ (jointly and separately) and a 1-day lag (corresponding to 2885 -min spells) of the two as well as by (standardized) changes in VIX $t$ and $\mathrm{BB}_{t}$. Table $\mathrm{A} 5$ in the Appendix provides descriptive statistics for these variables.

$$
\Delta f x_{t+1}^{c}=\alpha^{c}+\Delta f x_{t}^{c}+\sum_{k=1}^{K} \beta_{k} S_{k, t}+\gamma_{1} \mathrm{ME}_{t}+\gamma_{2} \mathrm{ME}_{t-288}+\varepsilon_{t}^{c}
$$

In order to better gauge the significance of our marketenvironment variables, regressions are based on 1.473 million observations, i.e., including the exchange-rate returns when no macroeconomic surprises are available. The VIX index is traded from 9:15 to 16:15 US East coast time. VIX $\mathrm{V}_{t}$ denotes prior-day closing values. $\mathrm{BB}_{t}$ refers to news disseminated between 00:05 and 23:55 on the day preceding $\Delta f x_{t+1}^{c}$. Of course, $\mathrm{VIX}_{t}$ and $\mathrm{BB}_{t}$ are going to grow older (and possibly less relevant) as we refer to $\Delta f x_{t+1}^{c}$ further into the next day.

Table 8 displays the results for the various versions of regression (6). For the sake of manageability, only the results for the market-environment variables are reported. Results for the surprise variables remain unchanged. 
Table 7 Surprises and policy regime

\begin{tabular}{|c|c|c|c|c|}
\hline \multicolumn{5}{|c|}{ Floor sample: 09/07/2011 to $12 / 31 / 2013$} \\
\hline & \multicolumn{2}{|c|}{ Obs: 454} & \multicolumn{2}{|c|}{ Obs: 454} \\
\hline \multirow[t]{2}{*}{ Dependent variable: $\Delta f x_{t+1}^{c}$} & \multicolumn{2}{|c|}{$c=E U R C H F$} & \multicolumn{2}{|c|}{$c=U S D C H F$} \\
\hline & $\beta_{k}$ & $p$ value & $\beta_{k}$ & $p$ value \\
\hline C & -0.002 & 0.370 & -0.013 & 0.086 \\
\hline$\Delta f x_{t}^{c}$ & -0.091 & 0.361 & -0.382 & 0.013 \\
\hline APP_St & 0.009 & 0.011 & 0.033 & 0.006 \\
\hline DEP_S $S_{t}$ & 0.016 & 0.000 & 0.061 & 0.000 \\
\hline$R^{2}$ & 0.094 & & 0.182 & \\
\hline Adjusted $R^{2}$ & 0.088 & & 0.176 & \\
\hline \multicolumn{5}{|c|}{ Abe sample: $12 / 01 / 2012$ to $12 / 31 / 2013$} \\
\hline & \multicolumn{2}{|c|}{ Obs: 205} & \multicolumn{2}{|c|}{ Obs: 205} \\
\hline \multirow[t]{2}{*}{ Dependent variable: $\Delta f x_{t+1}^{c}$} & \multicolumn{2}{|c|}{$c=$ EURJPY } & \multicolumn{2}{|c|}{$c=U S D J P Y$} \\
\hline & $\beta_{k}$ & $p$ value & $\beta_{k}$ & $p$ value \\
\hline C & -0.006 & 0.529 & -0.005 & 0.717 \\
\hline$\Delta f x_{t}^{c}$ & -0.152 & 0.629 & 0.385 & 0.280 \\
\hline APP_S $S_{t}$ & 0.032 & 0.022 & 0.070 & 0.002 \\
\hline DEP_S $S_{t}$ & 0.040 & 0.009 & 0.057 & 0.005 \\
\hline$R^{2}$ & 0.096 & & 0.196 & \\
\hline Adjusted $R^{2}$ & 0.082 & & 0.184 & \\
\hline
\end{tabular}

We recall that positive values of $\mathrm{VIX}_{t}$ and $\mathrm{BB}_{t}$ are associated with a favorable environment, while negative values reflect times where negative news dominates, and thus risk is high. VIX $\mathrm{VI}_{t}$ and $\mathrm{BB}_{t}$ bear the right sign in all four regressions. An increase in these variables is associated with a depreciation of the CHF or JPY. When introduced separately, $\mathrm{VIX}_{t}$ and $\mathrm{BB}_{t}$ appear to be significant in three out of four regressions. The sign and size of the coefficient of $\mathrm{VIX}_{t-288}$ and $\mathrm{BB}_{t-288}$ clearly suggest that we refer to the changes in these two variables. Results for specifications including the changes only are in the fourth and fifth panel of Table 8 .

All in all, we interpret these results as clear evidence that returns in EURCHF, EURJPY, and USDJPY are systematically influenced by changes in $\mathrm{VIX}_{t}$ and $\mathrm{BB}_{t}$. Coefficients are small. We should recall, however, that we are regressing 5 -min returns on daily variables. As a robustness check, we have also run regressions at a daily frequency. Generally speaking, results remain qualitatively similar to the ones reported in Table 8 (see Table A2 in the Appendix). The size of the $\triangle \mathrm{BB}_{t}$ coefficient in the EURCHF regression raises to 0.0006 (as compared to 0.0001 in Table 8 ), implying that a one standard deviation change in $\mathrm{BB}_{t}$ is associated with a $0.06 \%$ variation in the EURCHF. Similarly, a one standard deviation change in VIX $_{t}$ is associated with a $0.12 \%$ variation in the EURCHF. These are economically very substantial numbers.

The previous results suggest that market conditions have on average a significant impact on the CHF and JPY. Safe-haven currencies, however, are thought to respond in a particularly pronounced manner during times of extreme stress. Ranaldo and Söderlind (2010) find "indicative" evidence of this phenomenon by using a dummy variable for 21 extreme events between 1993 and 2007, covering natural disasters, financial crises and acts of war or terror. We proceed by expanding regression (6) with dummy variables that reflect extreme values of our market-environment conditions. Concretely, we create a dummy for extreme negative values of $\mathrm{BB}_{t}$ and one for extreme positive values of $\mathrm{BB}_{t}$ by setting

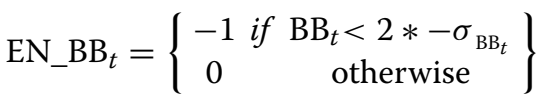

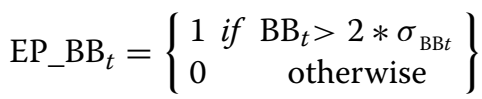

EN_VIX ${ }_{t}$ is defined in a similar manner. EP_VIX $t$ is actually a vector composed of $0 \mathrm{~s}$ only, as our standardized measure of VIX $t$ never gets higher than two standard deviations. 
Table 8 Role of the market environment

\begin{tabular}{|c|c|c|c|c|c|c|c|c|}
\hline \multicolumn{9}{|c|}{ Sample: $1 / 01 / 2000$ to $12 / 31 / 2013$} \\
\hline \multicolumn{9}{|c|}{ Obs: $1,472,832 ; 1,051,776$ if $\mathrm{VIX}_{t}$ is included } \\
\hline \multirow[t]{2}{*}{ Dependent variable: $\Delta f x_{t+1}^{c}$} & \multicolumn{2}{|c|}{$c=E U R C H F$} & \multicolumn{2}{|c|}{$c=U S D C H F$} & \multicolumn{2}{|c|}{$c=E U R J P Y$} & \multicolumn{2}{|c|}{$c=$ USDJPY } \\
\hline & $\beta_{k}$ & $p$ value & $\beta_{k}$ & $p$ value & $\beta_{k}$ & $p$ value & $\beta_{k}$ & $p$ value \\
\hline \multirow{2}{*}{\multicolumn{9}{|c|}{$\begin{array}{l}\text { Market-environment } \\
\text { measures }\end{array}$}} \\
\hline & & & & & & & & \\
\hline VIX $t_{t}$ & 0.002 & 0.000 & 0.000 & 0.924 & 0.006 & 0.000 & 0.003 & 0.000 \\
\hline$V I X_{t-288}$ & -0.002 & 0.000 & 0.000 & 0.772 & -0.006 & 0.000 & -0.003 & 0.000 \\
\hline $\mathrm{BB}_{t}$ & 0.000 & 0.001 & 0.000 & 0.113 & 0.000 & 0.484 & 0.000 & 0.132 \\
\hline $\mathrm{BB}_{t-288}$ & 0.000 & 0.272 & 0.000 & 0.802 & 0.000 & 0.715 & 0.000 & 0.181 \\
\hline VIX $t_{t}$ & 0.003 & 0.000 & 0.001 & 0.745 & 0.006 & 0.000 & 0.004 & 0.000 \\
\hline$V \mid X_{t-288}$ & -0.003 & 0.000 & 0.000 & 0.647 & -0.006 & 0.000 & -0.003 & 0.000 \\
\hline $\mathrm{BB}_{t}$ & 0.000 & 0.000 & 0.000 & 0.130 & 0.000 & 0.000 & 0.000 & 0.000 \\
\hline $\mathrm{BB}_{t-288}$ & 0.000 & 0.009 & 0.000 & 0.620 & 0.000 & 0.263 & 0.000 & 0.004 \\
\hline$\Delta \mathrm{VII} \mathrm{X}_{t}$ & 0.001 & 0.000 & 0.000 & 0.690 & 0.001 & 0.000 & 0.001 & 0.000 \\
\hline$\Delta \mathrm{BB}_{t}$ & 0.000 & 0.000 & 0.000 & 0.200 & 0.000 & 0.020 & 0.000 & 0.000 \\
\hline VIX $t_{t}$ & 0.003 & 0.000 & 0.000 & 0.890 & 0.006 & 0.000 & 0.004 & 0.000 \\
\hline$V I X_{t-288}$ & -0.003 & 0.000 & 0.000 & 0.988 & -0.006 & 0.000 & -0.004 & 0.000 \\
\hline EN_VIX $X_{t}$ & 0.000 & 0.856 & 0.001 & 0.177 & -0.002 & 0.024 & -0.001 & 0.054 \\
\hline EN_VIX ${ }_{t-288}$ & 0.000 & 0.990 & -0.001 & 0.205 & 0.002 & 0.013 & 0.001 & 0.091 \\
\hline $\mathrm{BB}_{t}$ & 0.000 & 0.000 & 0.000 & 0.013 & 0.000 & 0.183 & 0.000 & 0.044 \\
\hline $\mathrm{BB}_{t-288}$ & 0.000 & 0.006 & 0.000 & 0.039 & 0.000 & 0.543 & 0.000 & 0.001 \\
\hline EN_BB $t_{t}$ & 0.000 & 0.073 & -0.001 & 0.016 & 0.002 & 0.001 & 0.001 & 0.017 \\
\hline EN_BB ${ }_{t-288}$ & 0.000 & 0.820 & 0.001 & 0.028 & -0.001 & 0.478 & 0.000 & 0.758 \\
\hline $\mathrm{EP} \_\mathrm{BB}_{t}$ & 0.000 & 0.075 & 0.000 & 0.725 & 0.000 & 0.713 & 0.000 & 0.227 \\
\hline$E P \_B B_{t-288}$ & 0.000 & 0.150 & 0.001 & 0.030 & 0.000 & 0.995 & 0.000 & 0.105 \\
\hline
\end{tabular}

The two lower panels of Table 8 show the results. Here, again we also introduce 1-day lagged dummies for extreme conditions. By construction, coefficients for our extreme market conditions variables are expected to be positive. As far as EN_VIX $t$ is concerned, coefficients are either insignificant (CHF crosses) or bear the wrong sign (JPY crosses). On the contrary, extreme market environment conditions as measured by our Bloomberg index provide significant results. Both the CHF and JPY respond with an appreciation to extreme negative conditions as measured by $\mathrm{EN} \_\mathrm{BB}_{t}$. The response to extreme positive conditions instead is significant and makes sense only for the USDCHF exchange rate.

\subsection{Do macroeconomic surprises and the market environment interact?}

We next verify whether macroeconomic surprises and the market environment interact. One could in particular expect a larger impact of macroeconomic surprises on the CHF and JPY when the market environment is particularly positive or particularly negative.

$$
\Delta f x_{t+1}^{c}=\alpha^{c}+\Delta f x_{t}^{c}+\sum_{k=1}^{K} \beta_{k} S_{k, t}+\lambda_{k}\left(S_{k, t} * \mathrm{ME}_{t}\right)+\varepsilon_{t}^{c}
$$

We run regression (7) using both levels and changes in $\mathrm{VIX}_{t}$ and $\mathrm{BB}_{t}$ as market environment measures. Across the board, we find no convincing evidence that the market environment interacts with macroeconomic surprises. This result, however, must be interpreted with caution as it might well be crucially influenced by the unfortunate fact that we cannot measure $\mathrm{VIX}_{t}$ and $\mathrm{BB}_{t}$ at the 5-min frequency. We also ran regressions at a daily frequency. The outcome was unchanged.

\section{Conclusions}

We use 5-min returns for the CHF and JPY over a 13-year period encompassing the post-2007 crisis to investigate 
the link between macroeconomic surprises, general market environment, and monetary policy on the behavior of these two safe-haven currencies. Our analysis shows five clear results. First, safe-haven currencies are more sensitive to macroeconomic surprises than other currencies. This implies that macroeconomic surprises influence risk aversion and uncertainty. Second, the meaning of macroeconomic surprises for the two exchange rates is highly dependent on the state of the international economy. In particular, the impact of foreign surprises on CHF and JPY returns was strongly magnified in the crisis. Domestic surprises instead, maintain a relatively stable role across states of the economy. Third, the link between safe-haven currencies and macroeconomic surprises could not be broken by the unconventional monetary policies adopted in the crisis. Fourth, there are signs of asymetric reaction-surprises tend to produce somewhat larger appreciation movements than depreciation movements during the crisis-but not of nonlinearities. Fifth, we show that in addition safe-haven currencies react in a systematic way to measures of changes in the general market environment. Hence, macroeconomic surprises and the general market environment are two distinct channels through which international factors can affect safe-haven currencies. This result is robust to the use of two distinct measures of the market environment: the VIX and a variable based on Bloomberg wires.

\section{Endnotes}

${ }^{1}$ Between March 2009 and May 2010, the SNB intervened several times on the markets to contain the appreciation of the CHF (Swiss National Bank 2010 and 2011a). It also repeatedly made use of verbal interventions to manifest its discontent with the appreciation trend of the CHF and to signal that it stood ready to take further steps if needed. In September 2011, confronted with renewed strong appreciation pressures, the SNB introduced a formal exchange-rate floor vis-à-vis the EUR (Swiss National Bank 2011b). After lifting the exchange-rate floor in midJanuary 2015, the SNB stated that it "will continue to take account of the exchange rate situation in formulating its monetary policy" and that "if necessary, it will therefore remain active in the foreign exchange market" (Swiss National Bank 2015). With respect to the Japanese currency, the stark appreciation that followed the Lehman Brothers events prompted the G7 to issue a statement expressing specific concern about the "recent excessive volatility in the exchange rate of the yen" (G7 2008). The Bank of Japan (BoJ) started to intervene in September 2010 as the JPY hit a 15-year high against the USD. On
March 18, 2011, the G7 countries jointly intervened to dampen the JPY strength. Various waves of BoJ interventions also occurred in the following months. However, as Fig. 1 shows, the success of these measures was very limited. PM candidate Abe and the government that was appointed in December 2012 forcefully made the case for a further "unlimited" monetary policy easing to relaunch the economy and fight deflation. Indeed, the BoJ's easing stance became more resolute after the appointment of the new government. Markets clearly interpreted these signals as a game changer for the JPY (Wall Street Journal 2012).

${ }^{2}$ This is just for convenience. By that, we do not intend to suggest that this has corresponded to any fundamental change in the monetary policy strategy or institutional framework of either the BOJ or the SNB.

${ }^{3}$ This point can be illustrated with a fresh example. On October 302018 Eurostat released the estimate for Italian GDP growth in Q3 2018. At 0\%, estimated GDP growth fell below expectations. From a fundamental point of view, this should have led to a downward revision of expected future short-term interest rates in the euro area (as a matter of fact the euro-area wide GDP growth number also disappointed) and thus to lower capital market rates. German 10-year yields did indeed experience a decline of some $3 \mathrm{bp}$ following the announcement at $10 \mathrm{am}$. However, Italian 10 year bond rates actually increased. Over the day the yield went up by as much as $17 \mathrm{bp}$. As a consequence, the spread between 10 year Italian yields and 10 year German yields-a standard measure of redenomination risks in the euro area-jumped.

${ }^{4}$ See Neely and Dey (2010) for a broad survey of the literature on macroeconomic announcements and FX returns.

${ }^{5}$ As far as US unemployment is concerned, we use the inverse of $S_{k}$, so that the positive sign also corresponds to what one would expect to observe.

${ }^{6}$ Note that the fact that JPY and CHF regressions also contain some domestic explanatory variables does not bias in any way the comparison with AUD, CAD and GBP. In fact, running the JPY and CHF regressions without domestic variables leaves the results for foreign variables unchanged. This is due to the fact that foreign and domestic variables are released at different points in time.

\section{Appendix}


Table A1 Other currencies

\begin{tabular}{|c|c|c|c|c|c|c|c|c|c|c|}
\hline \multicolumn{11}{|c|}{ Sample: $1 / 01 / 2000$ to $12 / 31 / 2013$} \\
\hline \multirow{3}{*}{ Dependent variable: $\Delta f x_{t+1}^{c}$} & \multirow{2}{*}{\multicolumn{2}{|c|}{$\begin{array}{l}\text { Obs: } 2236 \\
c=\text { EURAUD }\end{array}$}} & \multirow{2}{*}{\multicolumn{2}{|c|}{$\begin{array}{l}\text { Obs: } 2521 \\
c=\text { USDAUD }\end{array}$}} & \multirow{2}{*}{\multicolumn{2}{|c|}{$\begin{array}{l}\text { Obs: } 2495 \\
c=\text { EURGBP }\end{array}$}} & \multirow{2}{*}{\multicolumn{2}{|c|}{$\begin{array}{l}\text { Obs: } 2613 \\
c=\text { USDGBP }\end{array}$}} & \multirow{2}{*}{\multicolumn{2}{|c|}{$\begin{array}{c}\text { Obs: } 2519 \\
c=\text { USDCAD }\end{array}$}} \\
\hline & & & & & & & & & & \\
\hline & $\beta_{k}$ & $p$ & $\beta_{k}$ & $p$ & $\beta_{k}$ & $p$ & $\beta_{k}$ & $p$ & $\beta_{k}$ & $p$ \\
\hline \multicolumn{11}{|l|}{ Euro area variables } \\
\hline Business climate & 0.003 & 0.640 & 0.010 & 0.060 & -0.008 & 0.040 & -0.002 & 0.740 & 0.003 & 0.560 \\
\hline \multicolumn{11}{|l|}{ German variables } \\
\hline Real GDP & -0.001 & 0.870 & 0.001 & 0.940 & 0.000 & 0.860 & -0.004 & 0.670 & 0.001 & 0.870 \\
\hline IFO business climate & -0.003 & 0.470 & 0.005 & 0.300 & -0.007 & 0.090 & 0.001 & 0.770 & 0.008 & 0.010 \\
\hline Retail sales & -0.001 & 0.760 & -0.007 & 0.160 & 0.003 & 0.520 & -0.002 & 0.740 & -0.001 & 0.910 \\
\hline Zew indicator & 0.000 & 0.980 & 0.003 & 0.490 & -0.005 & 0.140 & -0.002 & 0.580 & 0.001 & 0.810 \\
\hline \multicolumn{11}{|l|}{ US variables } \\
\hline Avg hourly earnings all & -0.012 & 0.230 & -0.019 & 0.050 & 0.002 & 0.740 & -0.006 & 0.490 & -0.017 & 0.050 \\
\hline Avg hourly earnings pro & -0.012 & 0.070 & -0.007 & 0.350 & 0.005 & 0.240 & 0.009 & 0.160 & 0.004 & 0.500 \\
\hline Emp.st. busin. cond. index & 0.000 & 1.000 & -0.001 & 0.910 & -0.002 & 0.540 & -0.002 & 0.830 & -0.009 & 0.150 \\
\hline Consumer confidence & 0.001 & 0.830 & -0.002 & 0.740 & 0.006 & 0.080 & 0.003 & 0.620 & -0.006 & 0.270 \\
\hline Phifed curr. busin. cond. & -0.003 & 0.580 & 0.002 & 0.820 & -0.007 & 0.170 & -0.003 & 0.630 & -0.012 & 0.240 \\
\hline Employment non-farm & 0.013 & 0.080 & 0.009 & 0.360 & 0.011 & 0.020 & 0.005 & 0.530 & 0.001 & 0.920 \\
\hline Existing home sales & -0.011 & 0.010 & -0.013 & 0.050 & 0.008 & 0.050 & 0.002 & 0.580 & -0.002 & 0.740 \\
\hline Housing starts & -0.004 & 0.330 & 0.000 & 0.960 & -0.004 & 0.160 & -0.001 & 0.900 & -0.007 & 0.140 \\
\hline Import goods and serv. & 0.011 & 0.080 & 0.005 & 0.400 & 0.001 & 0.810 & v0.003 & 0.560 & 0.003 & 0.670 \\
\hline Industrial production & -0.020 & 0.140 & -0.021 & 0.200 & 0.000 & 0.900 & -0.002 & 0.700 & -0.006 & 0.310 \\
\hline ISM non-manuf. & -0.003 & 0.550 & -0.004 & 0.600 & -0.003 & 0.650 & -0.003 & 0.590 & -0.007 & 0.580 \\
\hline ISM manuf. & -0.002 & 0.700 & -0.006 & 0.120 & -0.004 & 0.360 & -0.005 & 0.280 & -0.007 & 0.240 \\
\hline Comp.index leading ind. & 0.002 & 0.740 & 0.016 & 0.070 & -0.004 & 0.130 & 0.008 & 0.090 & 0.013 & 0.050 \\
\hline New home sales & 0.016 & 0.020 & -0.011 & 0.130 & 0.002 & 0.590 & -0.001 & 0.760 & 0.006 & 0.220 \\
\hline New orders dur. goods & 0.002 & 0.710 & -0.004 & 0.560 & 0.001 & 0.700 & -0.004 & 0.320 & -0.003 & 0.540 \\
\hline Productivity & 0.011 & 0.300 & -0.009 & 0.600 & -0.016 & 0.120 & -0.029 & 0.010 & -0.009 & 0.460 \\
\hline Retail sales & -0.006 & 0.290 & -0.004 & 0.620 & 0.004 & 0.420 & 0.004 & 0.500 & -0.005 & 0.430 \\
\hline Real GDP pre & 0.004 & 0.450 & 0.006 & 0.450 & 0.000 & 0.930 & 0.000 & 0.960 & 0.003 & 0.630 \\
\hline Real GDP adv & 0.002 & 0.850 & 0.010 & 0.430 & -0.005 & 0.210 & 0.003 & 0.640 & -0.009 & 0.330 \\
\hline Real GDP final & 0.001 & 0.910 & -0.008 & 0.340 & 0.010 & 0.060 & 0.003 & 0.700 & 0.006 & 0.540 \\
\hline Unit labor costs & 0.010 & 0.080 & -0.016 & 0.010 & 0.017 & 0.000 & -0.009 & 0.020 & -0.017 & 0.000 \\
\hline Unemployment rate & 0.003 & 0.610 & 0.109 & 0.500 & 0.001 & 0.790 & 0.001 & 0.830 & 0.008 & 0.180 \\
\hline
\end{tabular}


Table A2 Role of the market environment, daily frequency

\begin{tabular}{|c|c|c|c|c|c|c|c|c|}
\hline \multicolumn{9}{|c|}{ Sample: $1 / 01 / 2000$ to $12 / 31 / 2013$} \\
\hline \multicolumn{9}{|c|}{ Obs: 3637; 2909 if VIX $X_{t}$ is included } \\
\hline \multirow[t]{2}{*}{ Dependent variable: $\Delta f x_{t+1}^{c}$} & \multicolumn{2}{|c|}{$c=E U R C H F$} & \multicolumn{2}{|c|}{$c=$ USDCHF } & \multicolumn{2}{|c|}{$c=E U R J P Y$} & \multicolumn{2}{|c|}{$c=$ USDJPY } \\
\hline & $\beta_{k}$ & $p$ value & $\beta_{k}$ & $p$ value & $\beta_{k}$ & $p$ value & $\beta_{k}$ & $p$ value \\
\hline \multirow{2}{*}{\multicolumn{9}{|c|}{$\begin{array}{l}\text { Market-environment } \\
\text { measures }\end{array}$}} \\
\hline & & & & & & & & \\
\hline VIX $t_{t}$ & 0.006 & 0.000 & 0.003 & 0.289 & 0.018 & 0.000 & 0.010 & 0.000 \\
\hline VIX $t_{t-288}$ & -0.006 & 0.000 & -0.001 & 0.470 & -0.017 & 0.000 & -0.010 & 0.000 \\
\hline $\mathrm{BB}_{t}$ & 0.001 & 0.000 & -0.001 & 0.571 & 0.000 & 0.819 & 0.000 & 0.351 \\
\hline $\mathrm{BB}_{t-288}$ & -0.001 & 0.325 & -0.001 & 0.182 & 0.000 & 0.469 & 0.001 & 0.234 \\
\hline VIX $t_{t}$ & 0.007 & 0.000 & 0.002 & 0.216 & 0.018 & 0.000 & 0.010 & 0.000 \\
\hline VIX $X_{t-288}$ & -0.007 & 0.000 & -0.001 & 0.530 & -0.017 & 0.000 & -0.009 & 0.000 \\
\hline $\mathrm{BB}_{t}$ & 0.001 & 0.000 & 0.000 & 0.655 & 0.001 & 0.039 & 0.000 & 0.421 \\
\hline $\mathrm{BB}_{t-288}$ & -0.001 & 0.202 & -0.001 & 0.199 & 0.000 & 0.812 & 0.000 & 0.641 \\
\hline$\Delta \mathrm{VII} \mathrm{X}_{t}$ & 0.001 & 0.000 & 0.000 & 0.264 & 0.003 & 0.000 & 0.002 & 0.000 \\
\hline$\Delta \mathrm{BB}_{t}$ & 0.001 & 0.010 & 0.000 & 0.904 & 0.001 & 0.074 & 0.000 & 0.856 \\
\hline VIX $X_{t}$ & 0.007 & 0.000 & 0.002 & 0.306 & 0.019 & 0.000 & 0.010 & 0.000 \\
\hline VIX $X_{t-288}$ & -0.007 & 0.000 & 0.000 & 0.936 & -0.018 & 0.000 & -0.010 & 0.000 \\
\hline EN_VIX $X_{t}$ & -0.001 & 0.780 & 0.000 & 0.982 & 0.004 & 0.195 & 0.000 & 0.980 \\
\hline EN_VIX & 0.000 & 0.983 & 0.007 & 0.098 & -0.008 & 0.016 & -0.005 & 0.019 \\
\hline $\mathrm{BB}_{t}$ & 0.000 & 0.335 & -0.001 & 0.562 & 0.000 & 0.796 & 0.000 & 0.868 \\
\hline $\mathrm{BB}_{t-288}$ & 0.000 & 0.791 & -0.001 & 0.166 & 0.000 & 0.469 & 0.000 & 0.329 \\
\hline $\mathrm{EN} \_\mathrm{BB}_{t}$ & -0.004 & 0.263 & -0.005 & 0.479 & -0.010 & 0.019 & -0.001 & 0.524 \\
\hline $\mathrm{EN} \_B B_{t-288}$ & 0.011 & 0.302 & -0.003 & 0.587 & 0.007 & 0.053 & -0.005 & 0.255 \\
\hline $\mathrm{EP} \_\mathrm{BB}_{t}$ & -0.001 & 0.445 & 0.003 & 0.463 & 0.001 & 0.474 & 0.001 & 0.084 \\
\hline$E P \_B B_{t-288}$ & 0.000 & 0.931 & 0.003 & 0.105 & 0.000 & 0.495 & 0.001 & 0.187 \\
\hline
\end{tabular}


Table A3 Top ranking negative news according to Bloomberg on March 13 2011. (Source: Bloomberg Terminal)

1) Tepco, Toshiba, JR East May Be Among Most Hurt by Earthquake

2) Renault Spy Claims Sidelined as Prosecutor Opens Fraud Case

3) Nuclear Renaissance Threatened as Japan's Reactor Struggles

4) $\quad \checkmark$ Deaths in Japan Quake Top 500; Nuclear Fuel May Be Melting

5) Renaissance Threatened as Japanese Reactor Struggles

6) Death Toll From Japan Quake Nears 500; Radioactive Gas Released

7) Pressure, Radiation Rising at Japanese Reactors After Quake

8) Renault Security Manager Faces Fraud Charge; Spy Claims Dropped

9) Tokyoites Reeling From Quake Show Resilience With Daily Routine

10) *DANIEL MUDD RECEIVES WELLS NOTICE IN SEC PROBE OF FANNIE MAE

Tokyo Transport System Returns to Normal After Quake Disruption

Five Israelis Killed in Attack on West Bank Settlement Home

Refinery Margins Poised to Surge After Quake If History Is Guide

Quake Shutters Honda, Toshiba Plants; Damages Nissan Cars

Fannie Mae Ex-CEO Mudd May Face SEC Claims in Subprime Probe

Quake Shutters Plants at Honda, Toshiba; Damages Nissan Cars

Global Reinsurers May Sidestep Costs as Japan Faces Most Losses

China May Consider Japan Nuclear Accident in Future Energy Plans

Wikileaks Backers Lose Twitter Data Fight in Assange Probe

Asian Currencies Weaken on Japan Earthquake, Growth Concern

TNK-BP Fails to Replace BP in Rosneft Deal as New Offer Rejected

N.Y. Police Are Searching for Truck Involved in Fatal Bus Crash

Tokyo Electric Vents Radioactive Gas at Plant After Earthquake

Metals Demand in Japan May Drop as Factories Shut After Quake

Latest Death Toll Figures From Japan Tsunami Disaster top

Latest Death Toll Figures From Japan Tsunami Disaster

Oil Falls for Fifth Day as Japanese Quake May Limit Fuel Demand

Japan May Boost Grain Imports After Quake, StanChart's Ofon Says

Moody's May Lower Rating on Spanish Banks, Expansion Reports

Japan Quake Insured Losses May Reach \$34.2 Billion, AIR Says

China Guizhou Mine Explosion Death Toll Rises to 19, Xinhua Says

China Nuclear Project Unaffected by Japan Quake, Xinhua Reports

Ceragon Tumbles to 3-Month Low on Potential Affect of Earthquake

Clal Insurance Falls to Five Month Low on Japan Quake Damages

South Korea Sees Little Economic Impact From Japan Earthquake

Sapporo Shuts 3 Japan Plants; Kirin Assesses Quake Damage

HP Probe of Hurd's Departure Needs More Time, Lawyer Says

China Guizhou Mine Explosion Kills 13; Six Missing, RTHK Says 
Table A4 Descriptive statistics of selected variables

\begin{tabular}{|c|c|c|c|c|c|c|c|}
\hline Variable & Mean & Median & Max. & Min. & St. dev. & Skew. & Obs. \\
\hline \multicolumn{8}{|l|}{ Swiss variables } \\
\hline Retail sales YoY & -0.03 & 0.00 & 3.99 & -4.35 & 1.00 & -0.16 & 87 \\
\hline KOF barometer & 0.02 & 0.06 & 4.01 & -2.71 & 1.00 & 0.57 & 117 \\
\hline Manufacturing PMI & 0.07 & 0.14 & 2.75 & -4.09 & 1.00 & -0.40 & 118 \\
\hline Real GDP QoQ & 0.24 & 0.30 & 2.11 & -2.72 & 1.00 & -0.40 & 38 \\
\hline \multicolumn{8}{|l|}{ Japanese variables } \\
\hline Machinery orders MoM & 0.00 & -0.05 & 2.32 & -1.95 & 1.00 & 0.15 & 110 \\
\hline Retail sales YoY & 0.09 & 0.18 & 2.46 & -2.46 & 1.00 & -0.34 & 108 \\
\hline Household expenditures YoY & -0.02 & -0.12 & 2.51 & -2.45 & 1.00 & 0.28 & 115 \\
\hline Real GDP final QoQ & -0.23 & -0.03 & 0.91 & -5.53 & 1.00 & -4.08 & 30 \\
\hline \multicolumn{8}{|l|}{ Euro area variables } \\
\hline Business climate index & 0.09 & 0.16 & 2.83 & -2.99 & 1.00 & -0.10 & 119 \\
\hline \multicolumn{8}{|l|}{ German variables } \\
\hline Real GDP QoQ & 0.09 & 0.00 & 3.08 & -2.73 & 1.00 & 0.67 & 52 \\
\hline IFO business climate & 0.13 & 0.16 & 3.69 & -2.41 & 1.00 & 0.02 & 166 \\
\hline Retail sales MoM & -0.29 & -0.30 & 3.72 & -2.44 & 1.00 & 0.76 & 158 \\
\hline Zew indicator & 0.04 & 0.01 & 3.17 & -2.63 & 1.00 & 0.18 & 144 \\
\hline \multicolumn{8}{|l|}{ US variables } \\
\hline \multicolumn{8}{|l|}{ Avg hourly earnings all } \\
\hline Employees MoM & -0.40 & 0.00 & 1.34 & -2.69 & 1.00 & -0.02 & 47 \\
\hline \multicolumn{8}{|l|}{ Avg hourly earnings prod. workers } \\
\hline MoM & -0.09 & 0.00 & 3.01 & -2.25 & 1.00 & 0.28 & 85 \\
\hline \multicolumn{8}{|l|}{ Empire state business condition } \\
\hline Index & -0.11 & -0.03 & 2.09 & -3.20 & 1.00 & -0.37 & 119 \\
\hline Consumer confidence & 0.01 & 0.02 & 2.48 & -2.50 & 1.00 & -0.10 & 133 \\
\hline \multicolumn{8}{|l|}{ Phil. fed current. business } \\
\hline Conditions index & -0.14 & -0.09 & 1.96 & -3.64 & 1.00 & -0.40 & 132 \\
\hline \multicolumn{8}{|l|}{ Comp.index leading indicators } \\
\hline MoM & 0.06 & 0.00 & 2.91 & -2.08 & 1.00 & 0.42 & 132 \\
\hline Existing home sales & 0.04 & 0.00 & 3.51 & -3.72 & 1.00 & -0.47 & 133 \\
\hline Housing starts & 0.05 & -0.02 & 3.07 & -3.05 & 1.00 & -0.15 & 129 \\
\hline Industrial production MoM & -0.14 & 0.00 & 3.47 & -4.85 & 1.00 & -0.62 & 132 \\
\hline Import goods and serv. & 0.16 & 0.19 & 2.26 & -2.29 & 1.00 & -0.18 & 69 \\
\hline ISM non-manufacturing & 0.01 & 0.05 & 2.07 & -3.74 & 1.00 & -0.81 & 71 \\
\hline ISM manufacturing & 0.14 & 0.19 & 3.46 & -2.85 & 1.00 & 0.16 & 132 \\
\hline Productivity QoQ & 0.10 & 0.00 & 2.86 & -3.62 & 1.00 & -.64 & 44 \\
\hline New orders durable goods MoM & -0.12 & -0.09 & 2.42 & -3.80 & 1.00 & -0.44 & 132 \\
\hline Real GDP advanced QoQ & -0.13 & -0.32 & 2.06 & -2.22 & 1.00 & 0.15 & 44 \\
\hline Real GDP final QoQ & -0.28 & 0.00 & 2.14 & -2.49 & 1.00 & -0.13 & 44 \\
\hline US retsalex MOM S & -0.04 & 0.00 & 2.83 & -3.64 & 1.00 & -0.25 & 132 \\
\hline Unit labor costs QoQ & 0.06 & -0.03 & 5.06 & -2.82 & 1.00 & 2.35 & 44 \\
\hline Unemployment rate & 0.26 & 0.32 & 3.23 & -2.59 & 1.00 & -0.14 & 132 \\
\hline
\end{tabular}


Table A5 Descriptive statistics for $\mathrm{BB}_{t}, \mathrm{VIX}_{t}, \Delta \mathrm{BB}_{t}$, and $\Delta \mathrm{VIX}$

\begin{tabular}{llllllll}
\hline Variable & Mean & Median & Max. & Min. & St. dev. & Skew. & Obs. \\
\hline $\mathrm{BB}_{t}$ & 0.00 & -0.07 & 3.81 & -7.19 & 1.00 & -0.53 & $1^{\prime} 472^{\prime} 832$ \\
$\mathrm{VIX} \mathrm{X}_{t}$ & 0.00 & 0.21 & 1.27 & -6.55 & 1.00 & -1.95 & $1^{\prime} 051^{\prime} 776$ \\
$\Delta \mathrm{BB}_{t}$ & 0.00 & 0.00 & 5.25 & -5.17 & 0.06 & 0.46 & $1^{\prime} 472^{\prime} 831$ \\
$\Delta \mathrm{VIX} \mathrm{X}_{t}$ & 0.00 & 0.00 & 1.44 & -1.82 & 0.01 & -15.07 & $1^{\prime} 051^{\prime} 045$ \\
\hline
\end{tabular}

\begin{abstract}
Abbreviations
AUD: Australian dollar; BoJ: Bank of Japan; BST: British standard time; CAD: Canadian dollar; CBOE: Chicago board options exchange; CHF: Swiss Franc: EBS: Electronic broking services; FX: Foreign exchange; GBP: British pound; HAC: Heteroscedasticity and autocorrelation consistent; JPY: Japanese yen; S\&P: Standard and poor's; SNB: Swiss national bank; VIX: Volatility index
\end{abstract}

\section{Acknowledgements}

The authors are grateful to Irineu de Carvalho Filho, Christian Grisse, Carlos Lenz, Alexandre Swoboda, and seminar participants at the SNB, Geneva Graduate Institute and Fed San Francisco for valuable discussions as well as two anonymous referees for their suggestions. The views expressed are those of the authors and do not necessarily represent those of their affiliations.

\section{Funding}

Not applicable.

\section{Availability of data and materials}

Most data that support the findings of this study are available from Haver Analytics, EBS and Bloomberg but restrictions apply to the availability of these data, which were used under license for the current study, and so are not publicly available. On the contrary, the exchange-rate time series for the Australian Dollar, the Canadian Dollar and the British Pound stem from HistData.com, a freely available datasource.

\section{Authors' contributions}

All authors read and approved the final manuscript.

\section{Competing interests}

The authors declare that they have no competing interests.

\section{Publisher's Note}

Springer Nature remains neutral with regard to jurisdictional claims in published maps and institutional affiliations.

\section{Author details}

${ }^{1}$ University of St. Gallen, Department of Economics, St. Gallen, Switzerland.

${ }^{2}$ Alternate Member of the Governing Board, Swiss National Bank, Zurich, Switzerland. ${ }^{3}$ Economic Analysis Unit, Swiss National Bank, and University of Basel, Basel, Switzerland.

\section{Received: 27 February 2018 Accepted: 5 April 2019}

Published online: 23 May 2019

\section{References}

Andersen, T.G., Bollerslev, T., Diebold, F.X., Vega, C. (2003). Micro effects of macro announcements: real-time price discovery in foreign exchange. The American Economic Review, 93(1), 38-62.

Andersen, T.G., Bollerslev, T., Diebold, F.X., Vega, C. (2007). Real-time discovery in global stock, bond and foreign exchange markets. Journal of International Economics, 73, 251-277.

Auer, R. (2015). "A safe haven: international demand for Swiss francs during the euro area debt crisis". SNB Quarterly Bulletin, Q2, Swiss National Bank.

Bartolini, L., Goldberg, L., Sacarny, A. (2008). How economic news moves markets, current issues in economics and finance. Federal Reserve Bank of New York, 14(6).

Ben Omrane, W., \& Tanseli, S. (2017). Exchange rate volatility response to macroeconomic news during the global financial crisis. International Review of Financial Analysis, 52, 130-143.
Botman, D., de Carvalho Filho, I., Raphael, L. (2013). The curious case of the yen as a safe haven currency: a forensic analysis. IMF Working Paper, No. 228/13.

Cheung, Y.-W., Fatum, R., Yamamoto, Y. (2017). The exchange rate effects of macro news after the global financial crisis. Federal Reserve Bank of Dallas Working Paper, No. 305.

De Bock, R., \& de Carvalho Filho, I. (2015). The behavior of currencies during risk-off episodes. Journal of International Money and Finance, 53, 218-234.

Dominguez, KME (2003). The market microstructure of central bank intervention. Journal of International Economics, 59(1), 25-45.

Fatum, R., Hutchison, M., Thomas, W. (2012). Asymmetries and state dependence: the impact of macro surprises on intraday exchange rates. Journal of the Japanese and International Economies, 26(4), 542-560.

Fatum, R., \& Yamamoto, Y. (2016). Intra-safe haven currency behaviour during the global financial crisis. Journal of International Money and Finance, 66, 49-64.

G7 (2008). Statement of G7 Finance Ministers and Central Bank Governors, October 27

Goldberg, L., \& Grisse, C. (2013). Time variation in asset price responses to macro announcements. Federal Reserve Bank of New York Staff Reports, No. 626

Goldberg, L., \& Leonard, D. (2003). What moves sovereign bond markets? The effects of economic news on US and German yields, Current Issues in Economics and Finance. Federal Reserve Bank of New York, 9(9).

Gurkaynak, R.S., Sack, B., Swanson, E. (2005). The Sensitivity of Long-Term Interest Rates to Economic News: Evidence and Implications for Macroeconomic Models. American Economic Review, 95(1), 425-436.

Habib, M.M., \& Stracca, L. (2012). Getting beyond carry trade - what makes a safe-haven currency? Journal of International Economics, 87(1), 50-64.

Neely, C.J., \& Dey, S.R. (2010). A Survey of Announcement Effects on Foreign Exchange Returns. Review, Federal Reserve Bank of St. Louis, September/October, 417-463.

Pearce, D.K., \& Solakoglu, M.N. (2007). Macroeconomic news and exchange rates. Journal of International Financial Markets, Institutions and Money, 17(4), 307-325.

Ranaldo, A., \& Söderlind, P. (2010). Safe-Haven Currencies. Review of Finance, 14 385-407.

Swanson, E.T., \& Williams, J.C. (2014a). Measuring the effect of the zero lower bound on medium- and long-term interest rates. American Economic Review, 104(10), 3154-3185.

Swanson, E.T., \& Williams, J.C. (2014b). Measuring the Effect of the zero lower bound on yields and exchange rates in the UK and German economy. Journal of International Economics, 92(Supplement 1), S2-S21.

Swiss National Bank (2010). Annual Report 2009.

Swiss National Bank (2011a). Annual Report 2010.

Swiss National Bank (2011b). Press Release, September 6.

Swiss National Bank (2015). Press Release, January 15.

Wall Street Journal (2012). Yen's Fate Linked to Japan Elections, December 14.

Yeşin, P. (2016). Capital Flows and the Swiss Franc. SNB Working Paper, 2016-8.

\section{Submit your manuscript to a SpringerOpen ${ }^{\circ}$ journal and benefit from:}

- Convenient online submission

- Rigorous peer review

- Open access: articles freely available online

- High visibility within the field

- Retaining the copyright to your article

Submit your next manuscript at $\boldsymbol{\nabla}$ springeropen.com 